DANIELA DE ALMEIDA CASTELETI

EQUIVALÊNCIA DE ESTÍMULOS EM CRIANÇAS

PORTADORAS DA SÍNDROME DE APERT 
2011

UNIVERSIDADE DE SÃO PAULO

INSTITUTO DE PSICOLOGIA

PROGRAMA DE PÓS-GRADUAÇÃO EM PSICOLOGIA EXPERIMENTAL

\section{EQUIVALÊNCIA DE ESTÍMULOS EM CRIANÇAS PORTADORAS DA SÍNDROME} DE APERT

Daniela de Almeida Casteleti

Dissertação apresentada ao Programa de Pós-Graduação em Psicologia Experimental da Universidade de São Paulo (USP) como parte dos requisitos para obtenção do título de Mestre em Psicologia Experimental.

Área de concentração: Psicologia Experimental

Orientador: Prof. Dr. Gerson Yukio Tomanari

São Paulo 


\section{AUTORIZO A REPRODUÇÃO E DIVULGAÇÃO TOTAL OU PARCIAL DESTE TRABALHO, POR QUALQUER MEIO CONVENCIONAL OU ELETROONICO, PARA FINS DE ESTUDO E PESQUISA, DESDE QUE CITADA A FONTE.}

Casteleti, Daniela de Almeida.

Equivalência de estímulos em crianças portadoras de Síndrome de Apert / Daniela de Almeida Casteleti; orientador Gerson Yukio Tomanari. -- São Paulo, 2011.

$82 \mathrm{f}$.

Dissertação (Mestrado - Programa de Pós-Graduação em Psicologia. Área de Concentração: Psicologia Experimental) - Instituto de Psicologia da Universidade de São Paulo.

1. Discriminação condicional 2. Equivalência de estímulos 3 . Matching to sample 4. Acrocefalossindactilia I. Título. 


\title{
EQUIVALÊNCIA DE ESTÍMULOS EM CRIANÇAS PORTADORAS DA SÍNDROME DE APERT
}

\author{
Dissertação apresentada ao Instituto de Psicologia da \\ Universidade de São Paulo, como parte dos requisitos \\ para obtenção do título de Mestre em Psicologia
}

Área de concentração: Psicologia Experimental

Aprovado em:

Banca examinadora

$\operatorname{Prof}(a) . \operatorname{Dr}(a)$ :

Instituição: Assinatura:

$\operatorname{Prof}(a) . \operatorname{Dr}(a)$ :

Instituição: Assinatura:

$\operatorname{Prof}(a) . \operatorname{Dr}(a)$ :

Instituição: Assinatura: 
Aos meus queridos pais, com amor, admiração e gratidão pela compreensão, pelo carinho, pela presença e pelo incansável apoio ao longo da minha vida. 


\section{AGRADECIMENTOS}

Ao Gerson Tomanari, que, nos anos de convivência, muito me ensinou, contribuindo para meu crescimento científico e intelectual.

À Vera Raposo do Amaral, pelos inúmeros conselhos e orientações e por me abrir as portas da SOBRAPAR possibilitando, assim, a realização da pesquisa que contribuiu com este trabalho.

À amiga e muito querida Kátia Perez Ramos que, desde o início, confiou no meu trabalho e dedicação e me introduziu no mundo das pesquisas e da Análise Experimental do Comportamento. Muito obrigada por ajudar a semear a idéia inicial para este trabalho.

Aos colegas de laboratório, bem como a todos os colegas agregados de outros laboratórios da USP, que dedicaram seu tempo na leitura deste trabalho e muito contribuíram com suas sugestões e críticas.

À amiga e colega de laboratório Eliana Hamasaki que juntamente, com toda a atenção e apoio dispensado, apresentou sugestões, levantou questões e acrescentou idéias que contribuíram para a realização deste trabalho, tornando o árduo processo de pesquisa numa prazerosa busca de conhecimento.

À querida amiga e madrinha Nathali Sabino que, desde o início, me acompanha nesta jornada, dividindo alegrias e me dando suporte nas tristezas.

À Martha Hubner e Paula Debert que, contribuíram valiosamente para o refinamento deste trabalho.

Aos pacientes da SOBRAPAR, que aceitaram participar da pesquisa que acrescentou dados para este trabalho. 
À minha querida irmã Lívia, aos meus sobrinhos Júlia, Felipe e Camila, e ao meu pequeno David, que provavelmente sem saber, me deram incentivos em momentos essenciais.

Em especial ao meu amado Victor pelo amor, mimos, dedicação e tolerância em todos estes anos de convívio.

Ao CNPq pelo apoio financeiro que possibilitou a realização desse trabalho. 


\section{ÍNDICE}

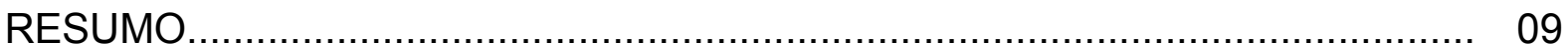

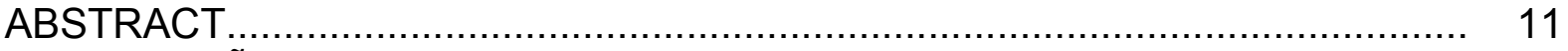

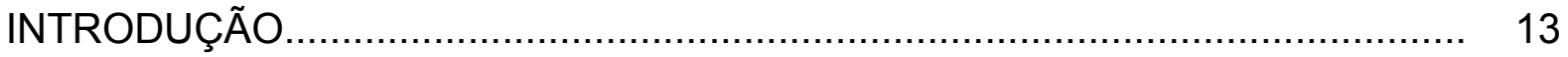

EXPERIMENTO 1

Método.

Resultados e Discussão...................................................... 35

EXPERIMENTO 2

Método.

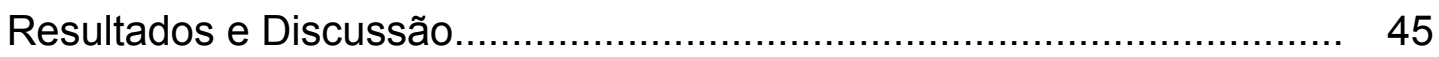

EXPERIMENTO 3

Método......................................................................................... 52

Resultados e Discussão .......................................................... 55

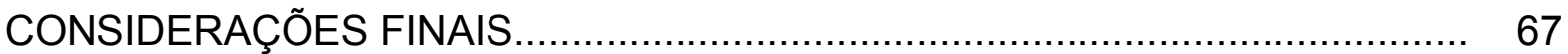

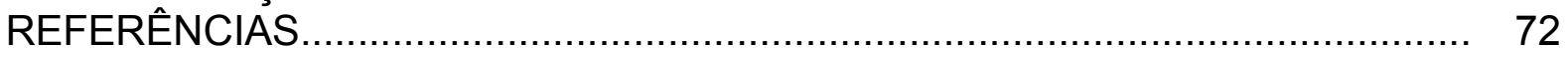

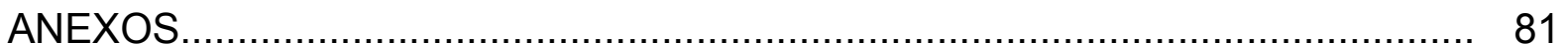




\section{RESUMO}

Casteleti, D.A. Equivalência de estímulos em crianças portadoras da Síndrome de Apert. 2011. 82f. Dissertação (Mestrado) - Instituto de Psicologia, Universidade de São Paulo, São Paulo.

O presente estudo investigou comportamentos simbólicos nos portadores de Síndrome de Apert por meio do paradigma da equivalência de estímulos, uma vez que este pode fornecer subsídios para a compreensão do comportamento humano complexo, tais como o comportamento simbólico e a linguagem. Foram propostos três experimentos cujos participantes, com idades entre 16 e 21 anos, foram submetidos aos Experimentos 1 e 2 (P1, P2 e P3) e submetidos ao Experimento 3 (P4 e P5). No Experimento 1, o objetivo foi verificar a formação de classes de estímulos equivalentes após o treino de relações condicionais, por meio de uma tarefa de matching to sample (MTS) com atraso de $0 \mathrm{~s}$ e três estímulos de comparação. Após o participante atingir um percentual de acerto de $94 \%$ no bloco, foram conduzidos testes de equivalência ( $C A$ ), simetria (BA e $C B$ ) e transitividade (AC). De maneira geral, houve falha nos testes, com relativa preservação do teste de simetria. No Experimento 2, os participantes foram expostos à tarefa de MTS com atraso de $0 \mathrm{~s}$ e três estímulos de comparação, mas estes e o estímulo modelo apresentavam-se inicialmente cobertos, tornando-se visíveis somente após a emissão de respostas de observação (RO's). Foram introduzidas RO's na tarefa de MTS, com o objetivo de identificar que tipos de controle (seleção ou rejeição) poderiam estar em operação na formação de classes de estímulos equivalentes. Nos testes, o participante P3 formou classes de equivalência, contudo, os participantes P1 e P2 continuaram a apresentar falha na formação de equivalência, com preservação do teste de simetria. No Experimento 3, foram apresentadas variações metodológicas com o objetivo de favorecer o estabelecimento de um ou de outro tipo de controle (seleção ou rejeição), durante o treino das relações condicionais e verificar os efeitos destas variações no desempenho obtido nos testes. O participante $\mathrm{P} 4$ foi submetido primeiramente à situação na qual a terceira RO produzia o estímulo correto em $80 \%$ das tentativas $\left(80 \% / 3^{\text {a }} \mathrm{S}+\right)$. Posteriormente 
à realização das tarefas sob esta condição, foi submetido à situação na qual a primeira RO produzia o estímulo correto em $80 \%$ das tentativas $\left(80 \% / 1^{\text {a }} \mathrm{S}+\right)$. $\mathrm{O}$ participante P5 foi exposto à ordem inversa: primeiramente à situação $80 \% / 1^{\text {a }} \mathrm{S}+\mathrm{e}$ posteriormente à situação $80 \% / 3^{\mathrm{a}} \mathrm{S}+$. Nos testes, em ambas as situações, o participante P4 foi capaz de aprender as relações de equivalência propostas pelo experimentador. Diferentemente, o responder do participante P5 não se apresentou sob controle discriminativo das contingências programadas pelo experimentador. De um modo geral, os resultados obtidos pelo presente estudo acrescidos das análises do teste PEABODY, sugerem que as dificuldades para a formação de classes de equivalência em participantes com baixo funcionamento lingüístico podem decorrer, em grande parte, de preparação e adaptação insuficiente de procedimentos para esse tipo de população.

Palavras-chave: discriminação condicional; equivalência de estímulos; matching to sample; cranioestenose; Síndrome de Apert. 
ABSTRACT

Casteleti, D.A. Stimulus equivalence in children with Apert Syndrome. 2011. 82f. Thesis (Master)- Instituto de Psicologia, Universidade de São Paulo, São Paulo.

The present study investigated the symbolic behaviors of patients with Apert Syndrome through the paradigm of stimulus equivalence, since it may provide a basis for understanding complex human behavior, such as symbolic behavior and language. It had been proposed three experiments which participants, aged between 16 and 21 years, were submitted to Experiments 1 and 2 (P1, P2 and P3) and to Experiment 3 (P4 e P5). In Experiment 1, the objective was to assess the formation of classes of equivalent stimuli after training of conditional relations, through a task of matching to sample (MTS) and delay of 0s and three comparison stimuli. After the participant reaches a $94 \%$ criterion for accuracy in the block, tests were conducted for equivalence (CA), symmetry (BA and $C B$ ) and transitivity (AC). In general, the participants failed the tests, with relative preservation of the symmetry test. In Experiment 2, the participants were exposed to the task of MTS with delay of Os and three comparison stimuli, but these and the sample stimulus were initially covered, becoming visible only after the observation responses (OR's) issuance. OR's were introduced in the MTS task, with the objective to assess what kind of different controls (selection and rejection) could be involved in the formation of classes of equivalent stimuli. In tests, participant P3 showed the formation of classes of equivalent stimuli; however, participants P1 and P2 had failed to form equivalence, preserving the symmetry test. In Experiment 3 were presented methodological variations with the objective of encouraging the establishment of one or another type of control (selection or rejection) during the training of conditional relations and verify the effects of these variations in performance obtained in tests. Participant P4 was, at first, subjected to the situation which the third OR produced the correct stimulus in $80 \%$ of attempts $(80 \%$ / 3rd S + ). After the tasks under this condition were performed, P4 underwent a situation which the first OR produced the correct stimulus in $80 \%$ of attempts $(80 \% / 1$ st $S+)$. The participant P5 was exposed to the reverse order: first of all to the situation $80 \% / 1$ st $S+$ and subsequently to the situation $80 \% / 3 \mathrm{rd} S+$ In the tests, in both situations, the participant P4 was able to learn the equivalence 
relations proposed by the experimenter. In contrast, the response of the participant P5 was not under discriminative control of the contingencies programmed by the experimenter. In general, the results obtained by this study plus the analysis of the PEABODY data suggests that difficulties in the formation of equivalence classes in participants with low language functioning may be due, in large part from inadequate preparation and adjustment procedures for this type of population.

Keywords: conditional discrimination, stimulus equivalence, matching to sample; craniosynostosis, Apert syndrome. 


\section{SÍNDROME DE APERT}

Dentre as cranioestenoses associadas a anomalias múltiplas, encontram-se aquelas relacionadas a anomalias de membros, conhecidas como acrocefalossindactilias (do grego akros = ponta, $k e f a l o s=$ crânio, $s y n=$ reunião, dáctilo $=$ dedo), que constituem um grupo de defeitos congênitos com similaridade fenotípica, evidenciada por cranioestenose, hipertelorismo ocular, proeminência nasal, ponta nasal caída, hipodesenvolvimento de face média e anomalias variáveis de mãos e pés (conforme se verifica na ilustração das Figuras 1 e 2). Neste grupo, de fundamental importância para este estudo, pode ser incluída a Síndrome de Apert (SA), também denominada acrocefalossindactilia tipo I, descrita em 1906 por E. Apert (Cohen, 2000).

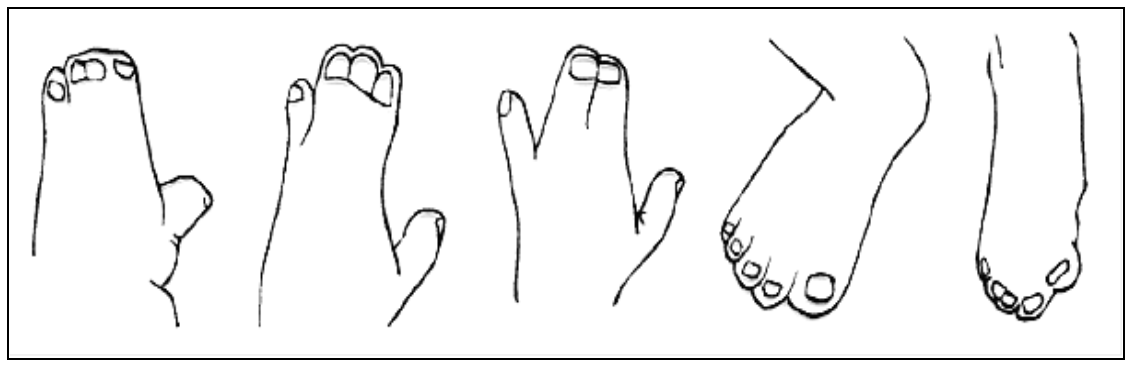

Figura 1 - llustração da sindactilia da síndrome de Apert (Fonte: www.apertbrasil.org)

A incidência da síndrome de Apert é de aproximadamente 1 em cada 65.000 nascimentos, afetando ambos os sexos igualmente e correspondendo a $4,5 \%$ de todos os casos de acroencefalosindactilia (Cohen, 1992). 


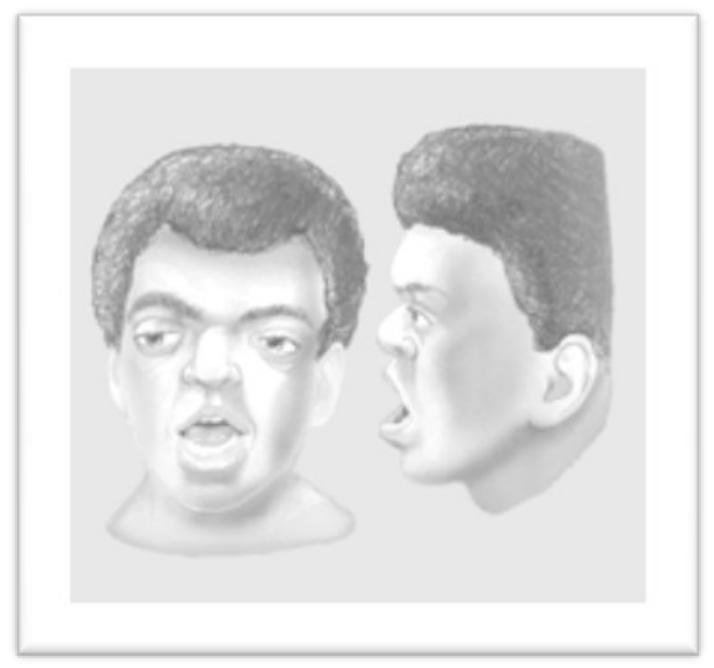

Figura 2 - llustração das principais características da síndrome de Apert (Fonte: www.apertbrasil.org)

Segundo Vogel e Motulsky (2000), a síndrome ocorre por uma alteração genética no período de gestação nos fatores de crescimento dos fibroblastos FGFR2 (célula do tecido conjuntivo formadora dos tecidos fibrosos do organismo), mapeado no cromossomo 10. É uma doença de carácter autossômico dominante, o que significa que, se um dos progenitores tiver a doença, o risco de ocorrência será de $50 \%$. No entanto, não existe uma causa específica. A mutação pode ser herdada de um dos progenitores que tiver a síndrome ou, pode ser uma mutação nova, espontânea. Ainda segundo os autores, a freqüência da mutação em pais não afetados aumenta à medida que aumenta a idade do pai, sobretudo a partir dos 35 anos.

De acordo com Yacubian-Fernandes e cols.(2005), a síndrome de Apert é uma forma rara de cranioestenose com fusão precoce de qualquer sutura craniana, mais freqüentemente a coronária, associada à hipoplasia (recuo) da face média, sindactilia (fusão) simétrica das mãos e pés e outras alterações.

As anormalidades intracranianas incluem ventriculomegalia, hidrocefalia franca, anomalias de corpo caloso, hipoplasia ou ausência de septo pelúcido, hipoplasia ou displasia do hipocampo e displasias ou distorções do córtex cerebral (Zeisel \& Roberts, 2003).

Segundo Yacubian-Fernandes e cols. (2005), as anormalidades intracranianas, a hipertensão intracraniana e as condições sócio-econômicas dos 
pacientes podem determinar o atraso no desenvolvimento mental, considerado comum na síndrome de Apert. Estes autores realizaram um estudo com 18 participantes com diagnóstico de síndrome de Apert, tendo como objetivo analisar as variáveis que possam influenciar no desenvolvimento cognitivo. Os participantes foram submetidos a exames de ressonância magnética - RM (a fim de identificar alterações no sistema nervoso central), avaliação cognitiva e análise social da família. A avaliação cognitiva foi realizada por meio da Escala de desenvolvimento de Gesell e Amatruda (1987), da Escala de Terman e Merril (1979), da Escala de Inteligência de Wechsler para crianças (WISC - III, 1994), da Escala de Inteligência de Wechsler para crianças pré-escolares (WPPSI, 1967) e da Escala de Inteligência de Wechsler para adultos (WAIS, 1981). Os valores de Quociente de Inteligência (QI) e Quociente de Desenvolvimento (QD) também foram obtidos. A análise social das famílias dos participantes foi feita usando o método proposto por Graciano e cols. (1999) que inclui o número de membros na família, grau de escolaridade, tipo de habitação, emprego e salário. Nos exames de RM foram observadas alterações encefálicas em $55,6 \%$ dos participantes. O Ql variou de 45 a 108 (sendo que o escore 70 é o limite inferior da normalidade) e estava correlacionado à classe sócioeconômica e ao nível de instrução dos pais, porém o QI não se correlacionou com as alterações encefálicas. Yacubian-Fernandes e cols. (2005) concluíram, assim, que a condição sócio-econômica e o nível de instrução dos pais se constituíram variáveis relevantes na determinação do desenvolvimento cognitivo dos participantes.

A despeito dos resultados do estudo conduzido por Yacubian-Fernandes e cols. (2005) não apresentarem correlação entre QI e as alterações encefálicas, há outros estudos que tentam correlacionar anormalidades intracranianas e o funcionamento intelectual significativamente abaixo da média [QI < 70] (Ciasca, Araujo, \& Simão, 2001; Cohen, \& Kreiborg, 1990; Patton, Goodship, Hayward, \& Lansdown, 1988; Renier, Arnaud, Cinalli, Sebag, Zerah, \& Marchac,1996). Para Cohen e Kreiborg (1990) e Patton e cols. (1988), os pacientes com síndrome de Apert apresentam diferentes graus de atraso no desenvolvimento cognitvo. Os autores sugerem que a má formação do sistema nervoso central, a hidrocefalia e o aumento da pressão intracraniana, podem ser responsáveis pela maioria dos casos. 
De acordo com Renier, Arnaud, Cinalli, Sebag, Zerah e Marchac (1996), os problemas de aprendizagem ocorrem com maior frequência nas cranioestenoses sindrômicas do que na população normal, sendo a síndrome de Apert relacionada com as taxas mais altas de problemas de aprendizagem.

\section{Análise Experimental do Comportamento}

De acordo com Matos (1999), saber ou conhecer é atuar sob controle discriminativo.

Para que o controle discriminativo se estabeleça, é necessária uma história de reforçamento diferencial: na presença de determinados estímulos, respostas ou classe de respostas, serão seguidas de reforçamento e, na ausência destes estímulos ou em presença de outras, estas mesmas respostas não serão seguidas de reforçamento. Quando o responder ocorre na presença de um dado estímulo e não de outro, dizemos que ele está sob controle discriminativo.

No caso de contingências tríplices (descritas convencionalmente como a relação entre os termos $S^{d}-R-S^{R}$ ou ambiente-comportamento-ambiente), por exemplo, um estímulo (uma luz verde) é a ocasião na qual uma resposta (bicar um disco na caixa experimental, no caso de pombos) é seguida por reforço (como alimento). $O$ efeito do reforço sobre essa resposta de bicar é que a mesma terá maior probabilidade de ocorrência, quando a luz verde estiver acesa. Esse tipo de contingência dá origem a discriminações simples. Utilizando o exemplo descrito acima, as discriminações simples são aprendizagens nas quais o estímulo antecedente (luz verde), que se tornou discriminativo para uma determinada resposta (resposta do pombo de bicar o disco), estabelece a ocasião em que uma determinada resposta, e não outra, é contingentemente seguida de um evento reforçador (alimento) (Barros, 1996; Skinner, 1953/2003; Todorov, 1985).

O responder discriminado pode, ainda, ocorrer sob controle de um outro estímulo, de tal forma que, a emissão de uma determinada resposta na presença de um estímulo discriminativo $\left(S^{d}\right)$ só será seguida de reforço a depender da presença de outro estímulo, o condicional $\left(\mathrm{S}^{\mathrm{c}}\right)$. . Apenas na presença desta combinação de dois estímulos $\left(\mathrm{S}^{\mathrm{d}}\right.$ e $\mathrm{S}^{\mathrm{c}}$ ), a resposta será seguida de reforço (Cumming \& Berryman 1965). 
O procedimento amplamente usado para o treino de discriminações condicionais é o procedimento Matching-to-Sample (MTS). O MTS compreende a apresentação sucessiva de tentativas que se iniciam com a apresentação de um único estímulo (estímulo modelo). Uma resposta de observação emitida perante o estímulo modelo (por exemplo, uma resposta de clicar o mouse do computador sobre o estímulo ou tocar o próprio estímulo em uma tela sensível ao toque do monitor do computador) produz dois ou mais outros estímulos em diferentes localizações (estímulos escolha). É exigido que o sujeito escolha um dos estímulos comparações a cada tentativa a depender do estímulo modelo apresentado. Os estímulos apresentados como S- em determinada tentativa podem ser designados como $\mathrm{S}+$ para outros estímulos-modelo em outras tentativas, alternando, portanto, a função positiva ( $\mathrm{S}^{+}$) ou negativa (S-) dos estímulos de escolha. A relação entre o estímulo modelo e o estímulo de escolha apropriado pode ser de identidade, quando as características físicas dos estímulos são idênticas ou simbólica (também chamada de arbitrária), quando modelo e escolha são fisicamente diferentes (de Rose, 1993).

No procedimento de MTS, o requisito é que o responder do participante esteja sob controle dos estímulos modelos apresentados, sucessivamente, ao longo das tentativas e dos estímulos de escolha apresentados, simultaneamente, em cada tentativa (Green \& Saunders, 1998). Se o participante se comporta de acordo com as contingências programadas, infere-se que as discriminações condicionais foram aprendidas e que as relações condicionais entre pares de estímulos foram estabelecidas. Desta maneira, os estímulos condicional e discriminativo são relacionados por meio das contingências de reforçamento estabelecidas durante o treino, daí o termo relação condicional (Barros, 1996; de Rose 1993; Sidman 1986).

Para a representação da relação entre estímulo modelo e de comparação convenciona-se a utilização de letras, por exemplo $A B$ : a primeira letra $(A)$ referindose ao conjunto de estímulos modelos, e a segunda letra $(B)$ referindo-se ao conjunto de estímulos de comparação. Além dessa representação alfabética, cada estímulo é representado numericamente (por exemplo, A1; A2; B1; B2). A representação numérica refere-se à relação condicional entre os estímulos; isto é, estímulos com a mesma representação numérica estão condicionalmente relacionados (por exemplo, A1B1; A2B2). 
Em 1971, Sidman empregando o modelo de discriminação condicional, ensinou um jovem de 17 anos, que apresentava dificuldades especiais severas, a selecionar desenhos condicionalmente à palavra ditada correspondente. No procedimento empregado por Sidman (1971), conforme pode se verificar no esquema da Figura 3 , as setas grossas sem preenchimentos representam relações de pareamento que o participante já dominava antes do início do experimento. A seta BD indica que o participante era, antes do início do procedimento, capaz de nomear as figuras que Ihe eram apresentadas. A seta contínua fina representa $o$ desempenho que foi ensinado ao participante: aprendeu a selecionar uma palavra impressa frente a uma palavra ditada $(A C)$ e foi capaz de, frente a palavras ditadas, escolher as figuras correspondentes (AB). As setas tracejadas indicam que, em decorrência desse ensino, o participante foi capaz de emparelhar palavras impressas com suas respectivas figuras $(\mathrm{CB}$ e $\mathrm{BC})$ e ler oralmente estas palavras (CD). Foram ensinadas 20 relações condicionais entre modelos auditivos (A palavra ditada) e modelos impressos de figuras (B) e entre A (palavra ditada) e C (palavra impressa). Os estímulos utilizados por Sidman (palavras faladas, palavras escritas e figuras) não compartilhavam nenhum tipo de característica física, não constituindo, portanto, uma classe de estímulos por similaridade física. A relação entre eles era arbitrária, com compartilhamento de respostas comuns. 


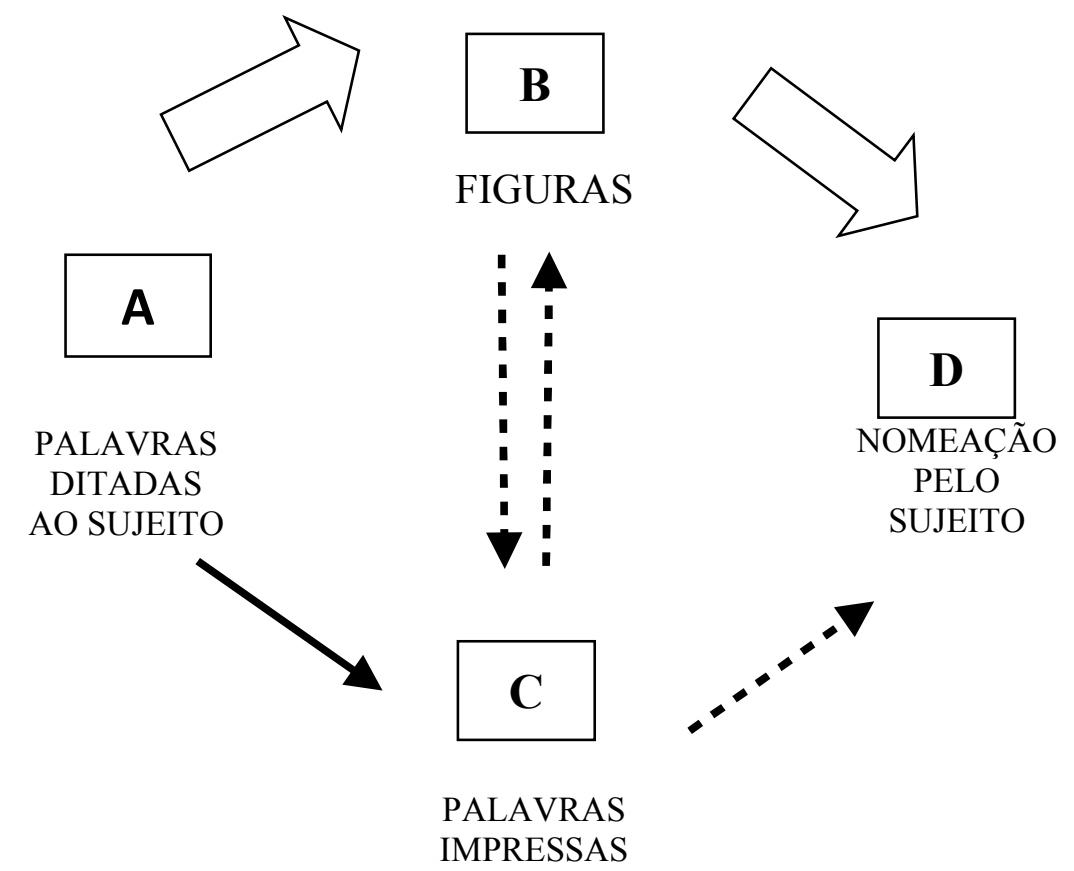

Figura 3. Diagrama do experimento realizado por Sidman (1971).

Ao término do experimento, Sidman observou que o jovem havia aprendido, além da relação entre palavras faladas e palavras escritas, a relação inversa (palavras escritas e palavras faladas), assim como a relacionar figuras às palavras escritas, sem ter sido diretamente ensinado a fazer tais relações. Com o procedimento usado em 1971, Sidman verificou que, além de relações estabelecidas via treino direto, outras relações emergiram sem a necessidade de tal treino e, ainda, que estes estímulos eram intercambiáveis (Catania, 1999; Sidman, 1994).

As relações emergentes descritas, neste primeiro estudo, por Sidman (1971) podem ser definidas como relações entre estímulos que emergem como novo comportamento a partir do ensino de outras relações (principalmente relações condicionais) entre estímulos, e não adquiridas a partir de reforçamento diferencial (Catania, 1999; de Rose, 1993). Um organismo treinado a relacionar condicionalmente estímulos fisicamente distintos pode passar a estabelecer novas relações condicionais entre os mesmos sem qualquer treino adicional (Sidman, Kirk, \& Willson-Morris, 1985; Sidman \& Tailby, 1982; Sidman, Willson-Morris, \& Kirk, 1986; Spradlin, Cotter, \& Baxley, 1973).

Sidman e Taliby (1982) propuseram que a emergência de relações condicionais não treinadas tem sido tomada como indicativo de que esses estímulos tornaram-se equivalentes, formando as chamadas classes de estímulos equivalentes 
ou classes de equivalência. Segundo estes autores, para avaliar se relações condicionais são também relações de equivalência é necessário testar a emergência de relações que documentam as propriedades de reflexividade, simetria e transitividade (Sidman \& Tailby, 1982). Isso deve ocorrer em uma situação sem que tais desempenhos precisem ser ensinados anteriormente.

A propriedade de reflexividade se constata por meio da relação condicional que cada estímulo mantém consigo mesmo, ou seja, quando as comparações corretas são iguais ao modelo (por exemplo, AA, BB e, assim por diante). A simetria é a bidirecionalidade das relações condicionais, isto é, o estímulo que serviu de comparação na relação treinada pode servir de modelo e vice-versa (por exemplo: se, no treino a relação foi $A B$, no teste a relação passa a ser $B A$ ). Para avaliar a terceira propriedade, de transitividade, é necessário o ensino de duas relações condicionais, de tal forma que cada relação tenha um estímulo comum, isto é, se $A B$ e BC, então testes de transitividade devem evidenciar que o estímulo A relaciona-se com estímulo $C(A C)$ sem qualquer treino explícito. A relação denominada de "equivalência" corresponde à combinação de simetria e transitividade, ou reversão da transitividade (CA). No caso de emergência das relações de reflexividade, simetria e transitividade, então a relação equivalência/reversão da transitividade (CA) deve também emergir, relação esta que é o teste definitivo da formação da classe de equivalência (Moreira,Todorov, \& Nalini, 2006).

Se os resultados obtidos nos testes das propriedades de equivalência forem positivos, elas denotam que os estímulos envolvidos se constituem numa classe de estímulos equivalentes. As classes de estímulos equivalentes devem incluir todas as relações possíveis entre seus membros (vide Figura 4). Este modelo básico pode ser estendido para classes com quatro ou mais membros. A Figura 4 apresenta uma ilustração das propriedades citadas acima: 


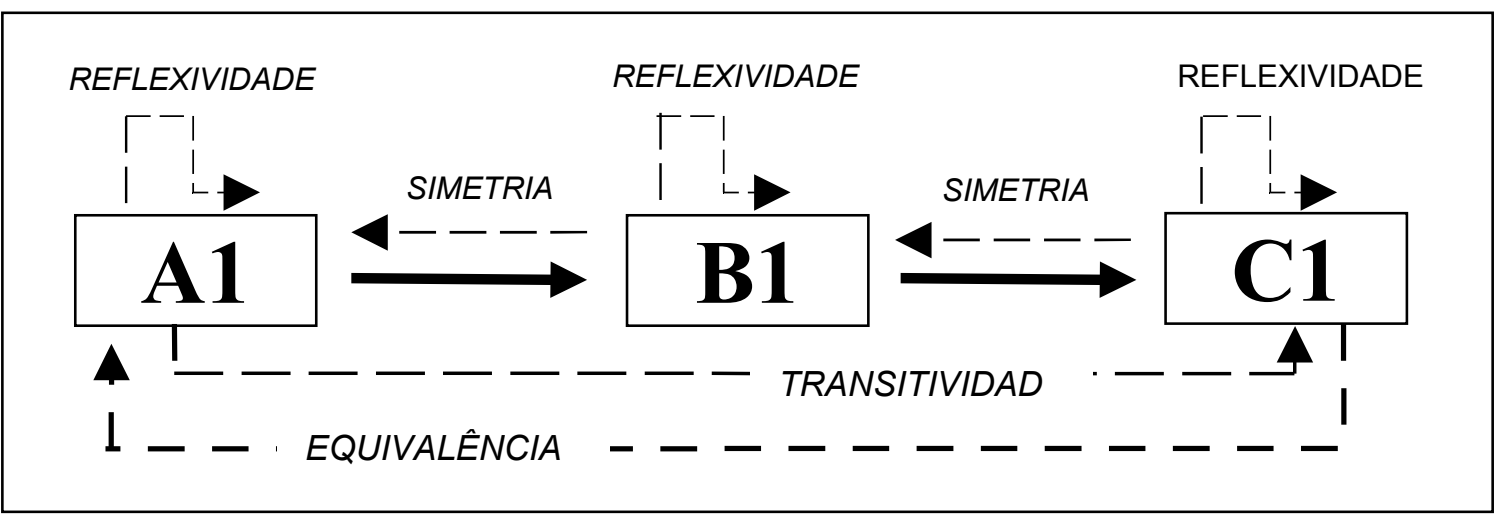

Figura 4. llustração das propriedades definidoras de classes de equivalência segundo Sidman e Taliby (1982). As setas cheias indicam as relações treinadas entre os estímulos A1, B1 e C1. As setas pontilhadas indicam as relações testadas.

A metodologia nos estudos sobre equivalência de estímulos, portanto, envolve um conjunto de relações condicionais treinadas diretamente, com conseqüências diferenciais para escolhas corretas e incorretas e em seguida, a aplicação de testes para verificar a emergência de novas relações condicionais (Green \& Saunders, 1998).

A pesquisa em equivalência de estímulos, crescente desde o trabalho inaugural de Sidman, em 1971, e a posterior sistematização metodológica (Sidman, Rausin, Lazar, Cunninghan, Taliby, \& Carrigan,1982; Sidman \& Taliby, 1982) é uma área de extrema importância científica e social para a análise Experimental do Comportamento, por suas pesquisas envolvendo processos comportamentais complexos (tais como a linguagem, a noção de "significado" e dos comportamentos simbólicos, em geral), tanto em indivíduos com desenvolvimento típico como em indivíduos com desenvolvimento atípico (de Rose, Mcllvane, Dube, Galpin, \& Stoddard, 1988; Matos, \& D'Oliveira, 1992).

Alguns estudos sobre equivalência de estímulos demonstram que indivíduos com atraso de desenvolvimento mostram dificuldade em desenvolver repertórios de formação de conceitos e comportamento simbólico. Os estudos desenvolvidos por Devany, Hayes e Nelson (1986) são amplamente citados como evidências da dificuldade de obtenção de classes de equivalência com participantes com baixo funcionamento lingüístico (crianças e adolescentes com desenvolvimento severo e atipicamente atrasado, por exemplo). De acordo com estes autores, participantes humanos com severas limitações de repertório lingüístico ou sujeitos não-humanos 
submetidos aos procedimentos tradicionais de treino e teste não apresentaram evidências (ou apresentaram indícios insuficientemente convincentes) de formação de classes, ao passo que participantes humanos com funcionamento lingüístico típico apresentam corriqueiramente desempenhos consistentes com os previstos para a demonstração de equivalência quando são submetidos aos procedimentos tradicionais de treino e teste (Devany, Hayes \& Nelson, 1986).

A partir dos estudos citados acima e de outros da área, alguns teóricos (Dugdale \& Lowe, 1990; Hayes, 1991; Horne \& Lowe, 1996, Bentall, Beasty \& Lowe, 1985) passaram a especular que o fenômeno da formação das classes de equivalência seria um produto da linguagem ou, mais especificamente, produto de repertórios de nomeação. Contrariamente à posição de Sidman, Horne e Lowe (1996) argumentam que a mediação por nomeação pode ser não só uma forma efetiva de facilitar a emergência de classes equivalentes, como também que seria responsável pela origem do repertório comportamental complexo a partir do qual se infere a equivalência (Tomanari, 2005).

Enquanto que para Hayes (1991), a equivalência surge como produto da experiência social dos indivíduos, especialmente aquelas relacionadas à linguagem (o desenvolvimento da linguagem possibilita o surgimento de classes de equivalência), para Sidman (1994), as origens da formação de classes de equivalência estão nas contingências de reforço presentes na relação entre o organismo e o seu ambiente. Para este autor, as classes de equivalência possibilitam o desenvolvimento da linguagem.

Diferentemente destes estudos que postulam que a formação de classes de equivalência seria produto de repertórios de nomeação( Dugdale \& Lowe, 1990; Hayes, 1991; Horne \& Lowe, 1996, Bentall, Beasty \& Lowe, 1985), os estudos de Carr, Wilkinson, Blackman e Mcllvane (2000), LeBlanc e cols. (2003), Barros e cols. (2005), Maguire e cols. (1994), apresentaram evidências de que mesmo crianças com baixo funcionamento lingüístico exibem classes de equivalência, justificando-se assim a continuidade de pesquisas com sujeitos com nenhum ou pouco repertório lingüístico e apontando para o fato de que, talvez, estes organismos sejam de fato capazes de apresentar comportamentos adaptativos não diretamente treinados em função da aprendizagem de relações entre eventos arbitrariamente relacionados. 
Sendo assim, baseado nessa discrepância entre os resultados obtidos envolvendo processos comportamentais complexos, tanto em crianças com desenvolvimento típico como em pessoas portadoras de deficiências no desenvolvimento, é possível que a posição dos teóricos que postulam a linguagem ou a nomeação como fonte das classes de equivalência seja precipitada.

De acordo com Horne e cols. (2007), os dados disponíveis na literatura não encerram a questão de se a nomeação é imprescindível para a formação de novas classes de estímulos, mas ressaltam o papel facilitador do ensino de uma resposta de nomeação comum na emergência de relações de equivalência.

Os dados de Tomanari, Sidman, Rubio e Dube (2006), adicionam evidências de que embora a nomeação possa exercer um papel facilitador, não é necessária para a formação de classes de equivalência.

Sobre este debate, Sidman (2000), afirma que a linguagem tem um papel relevante na formação das classes de equivalência, mas é preciso entender como esta contribui para a capacidade de síntese, abstração e categorização. O autor sugere que a nomeação pode facilitar a emergência de relações de equivalência, mas isso não significa dizer que só os indivíduos que nomeiam demonstram equivalência de estímulos, e portanto, não significa dizer que só os indivíduos com funcionamento lingüístico típico são capazes de demonstrar relações de equivalência.

Para Wikinson e Mcllvane (2001), a não obtenção deste repertório ou ainda, as dificuldades para encontrar classes de equivalência em participantes com baixo funcionamento lingüístico podem estar menos relacionado à capacidade de simbolizar desta população, mas, é possível que possa decorrer de características do arranjo experimental, das tarefas de treino ou de avaliação.

A adoção do paradigma de equivalência de estímulos nas pesquisas que visam investigar processos cognitivos e simbólicos de sujeitos com atraso no desenvolvimento pode contribuir muito para o conhecimento das variáveis envolvidas no processo de estabelecimento dos comportamentos ditos simbólicos, já que permite a observação e mensuração de algumas variáveis, necessárias ou suficientes, envolvidas na aquisição das habilidades cognitivas que envolvam aprendizagem de relações entre estímulos. 
A Teoria da Coerência de Topografia de Controle de Estímulos (Dube \& Mcllvane,1996; Mcllvane \& Dube 2003; Mcllvane, Serna, Dube, \& Stromer, 2000), que tem como base a noção de topografia de controle de estímulos (TCE)([Ray, 1969), parte do fato de que, todos os estímulos são inerentemente complexos, com uma grande quantidade de propriedades e características que podem vir a controlar o comportamento do sujeito. Sendo assim, em uma tarefa envolvendo treino discriminativo, múltiplas relações de controlem podem coexistir (algumas vezes conflitantes com as relações planejadas pelo experimentador) o que dificulta a aprendizagem das relações que supostamente deveriam estar sendo aprendidas.

Dube e Mcllvane (1996) propõem que o MTS pode induzir diferentes topografias de controle de estímulos como, por exemplo, controles pela posição, por atributos comuns, por características semelhantes em estímulos não idênticos e, principalmente, controle dos tipos modelo- $S+$ e modelo-S-. O controle por seleção refere-se ao responder predominantemente controlado pelo $S+$, ou seja, a escolha do sujeito é restrita ao estímulo de comparação determinado como o "correto" pelo experimentador, independentemente da exibição dos demais estímulos de comparação. Por sua vez, o controle por rejeição refere-se ao responder que é predominantemente controlado pelo S-, ou seja, a escolha do sujeito é determinada por quaisquer outros estímulos que não sejam aquele determinado como o "incorreto".

Os tipos de controle (rejeição ou seleção) no treino de discriminações condicionais são especialmente importantes para pesquisadores que investigam a aquisição deste repertório e que, além disso, testam a formação de classes de estímulos equivalentes.

Segundo a análise de Carrigan e Sidman (1992) e Johnson e Sidman (1993), há maior probabilidade de os participantes apresentarem as relações de equivalência programadas pelo experimentador quando, durante as tentativas de um treino de discriminações condicionais, as respostas de escolha desses participantes estiveram sob controle por seleção. Por outro lado, quando as respostas de escolha desses participantes estiverem sob controle por rejeição, há maior probabilidade de eles exibirem fracassos em tais relações de equivalência, presumivelmente por terem formado outras relações, incoerentes com aquelas que estão sendo avaliadas. Ainda assim, segundo esses autores, os testes de simetria seriam os únicos a serem 
preservados sob quaisquer das condições descritas no parágrafo anterior (por exemplo, respostas de escolha sob controle por seleção ou sob controle por rejeição, durante as tentativas de treino).

Sendo assim, identificar os diferentes tipos de controle mantidos pelas contingências de reforçamento permite o desenvolvimento de procedimentos que aumentem a probabilidade de ocorrência de respostas sob o controle planejado pelo experimentador e, desta maneira, diminui a probabilidade de ocorrência de respostas sob controles espúrios. Ainda, de acordo com a teoria da coerência das topografias de controle de estímulo, a variabilidade característica de controles espúrios, por exemplo, poderia ser reduzida ou eliminada por meio de um maior controle experimental sobre os diferentes tipos de controle estabelecidos no treino das relações condicionais.

Sob essa perspectiva, o presente estudo teve como objetivos realizar uma pesquisa no âmbito da Análise Experimental do Comportamento com foco na área de saúde, mais especificamente investigando processos simbólicos nos portadores de Síndrome de Apert por meio do paradigma da equivalência de estímulos.

Para tanto, foram propostos três experimentos, conforme detalhar-se-á na seção seguinte. 


\section{EXPERIMENTO 1}

Neste experimento, o objetivo foi verificar a formação de classes de estímulos equivalentes ao longo do treino de relações condicionais e dos testes. Para tanto, foram inicialmente treinadas seis relações condicionais: três relações $A B$ e três relações $B C$ (A1B1, A2B2, A3B3, B1C1, B2C2 e B3C3). Após o participante atingir um critério de acerto descrito a seguir, sem interrupção da sessão, foram conduzidos testes de equivalência ( $C A)$, simetria (BA e $C B$ ) e transitividade ( $A C)$.

\section{MÉTODO}

\section{Participantes}

Participaram do Experimento 1 três pacientes portadores da SA, provenientes do hospital SOBRAPAR que desenvolve pesquisas e oferece apoio à reabilitação crânio-facial, sem histórico de participação em pesquisas de psicologia e que se dispuseram a participar da presente investigação, juntamente com a autorização de familiares ou responsáveis pelos mesmos.

Antes da realização do experimento, familiares ou responsáveis dos participantes leram e assinaram o Termo de consentimento livre e esclarecido (Anexo 1). Os participantes, daqui em diante nomeados pelas siglas $\mathrm{P} 1, \mathrm{P} 2$ e $\mathrm{P} 3$, estão caracterizados na Tabela 1 , com idade cronológica, idade equivalente de acordo com repertório lingüístico avaliado pelo PEABODY (Dunn \& Dunn, 1981), classificação, segundo a avaliação por meio do PEABODY e sexo. 
Tabela 1. Descrição dos participantes do Experimento 1.

\begin{tabular}{|c|c|c|c|c|}
\hline Participante & $\begin{array}{l}\text { Idade } \\
\text { cronológica } \\
\text { no dia da } \\
\text { aplicação do } \\
\text { teste } \\
\text { PEABODY }\end{array}$ & $\begin{array}{l}\text { PEABODY - } \\
\text { idade } \\
\text { equivalente }\end{array}$ & Classificação & Sexo \\
\hline P1 & $\begin{array}{l}16 \text { anos e } 0 \\
\text { meses }\end{array}$ & $\begin{array}{l}\text { Acima de } 17 \\
\text { anos e } 11 \\
\text { meses }\end{array}$ & Normal- alta & Masc \\
\hline P2 & $\begin{array}{l}17 \text { anos e } 7 \\
\text { meses }\end{array}$ & $\begin{array}{l}12 \text { anos e } 8 \\
\text { meses }\end{array}$ & $\begin{array}{l}\text { Moderadamente } \\
\text { Baixa }\end{array}$ & Fem \\
\hline P3 & $\begin{array}{l}21 \text { anos e } 3 \\
\text { meses }\end{array}$ & $\begin{array}{l}12 \text { anos e } 8 \\
\text { meses }\end{array}$ & $\begin{array}{l}\text { Moderadamente } \\
\text { Baixa }\end{array}$ & Fem \\
\hline
\end{tabular}

\section{Local e equipamentos}

A pesquisa foi realizada em uma sala especialmente reservada para esta finalidade e livre de barulhos advindos do hospital. Na sala, havia um computador com o software Match! (Tomanari \& Capócio, 2008) instalado e que foi utilizado para controlar, durante as sessões experimentais, a apresentação randômica dos estímulos no monitor ao participante, o registro das respostas emitidas pelo participante e a liberação de conseqüências. Foi usado também um monitor LCD touchscreen modelo 1515L (TYCO/ELO TouchSystems). A tela sensível atua com resolução de 1024 X768 a 75 hz em monitor colorido (SVGA) de 15 polegadas.

\section{Estímulos}

Foram utilizados nove estímulos visuais, cujas dimensões na tela eram de aproximadamente $2,0 \mathrm{~cm} \times 2,0 \mathrm{~cm}$. Os estímulos foram aleatoriamente distribuídos em três conjuntos ( $A, B$, e $C$ ) de três estímulos cada. Os estímulos serão aqui designados por A1, A2, A3, B1, B2, B3, C1, C2 e C3 (Quadro 1). Os estímulos foram gentilmente cedidos pelo Dr. William Dube da University of Massachusetts Medical School - Shriver Center. 
Quadro 1. Estímulos utilizados na tarefa de MTS utilizando o aplicativo Match!

(1)

\section{Materiais}

Foram utilizados como itens reforçadores brinquedos e cosméticos hipoalergênicos apropriados para a faixa etária da população previamente selecionados em entrevista com os participantes. $\mathrm{O}$ acesso aos itens reforçadores era condicionado unicamente à finalização da tarefa e independiam do desempenho dos participantes durante o treino.

\section{Procedimento}

Os participantes foram expostos à tarefa de MTS arbitrário com atraso de $0 \mathrm{~s}$. Inicialmente foram treinadas seis relações condicionais: três relações $A B$ e três relações $B C$ (A1B1, A2B2, A3B3, B1C1, B2C2 e B3C3).

$\mathrm{Na}$ tarefa, tanto durante o treino como nos testes, um estímulo era apresentado no centro da tela (estímulo modelo). Diante do estímulo modelo exibido 
na tela, o participante deveria clicar sobre o mesmo. Tal resposta era seguida do desaparecimento do estímulo modelo e da apresentação de três estímulos de comparação, alinhados na parte inferior da tela. Para escolher o estímulo de comparação, o participante deveria também clicar sobre a figura do mesmo.

Durante as tentativas de treino, cada resposta aos estímulos designados como "corretos" (S+) foi seguida da apresentação de uma figura colorida no canto superior direito da tela por 1,5 s - uma "carinha feliz". Respostas aos estímulos designados como "incorretos" (S-) foram classificadas como "erros" e foram seguidas da apresentação de outra figura colorida no canto superior direito da tela por 1,5 s - uma "carinha triste" (ver ilustração do Quadro 2).

Não houve conseqüência diferencial programada nos blocos de testes.

Tanto na fase de treino como na fase de testes, o mesmo estímulo modelo não foi apresentado mais do que três tentativas consecutivas. As tentativas eram separadas por um intervalo (IET) de 0,5 s. 


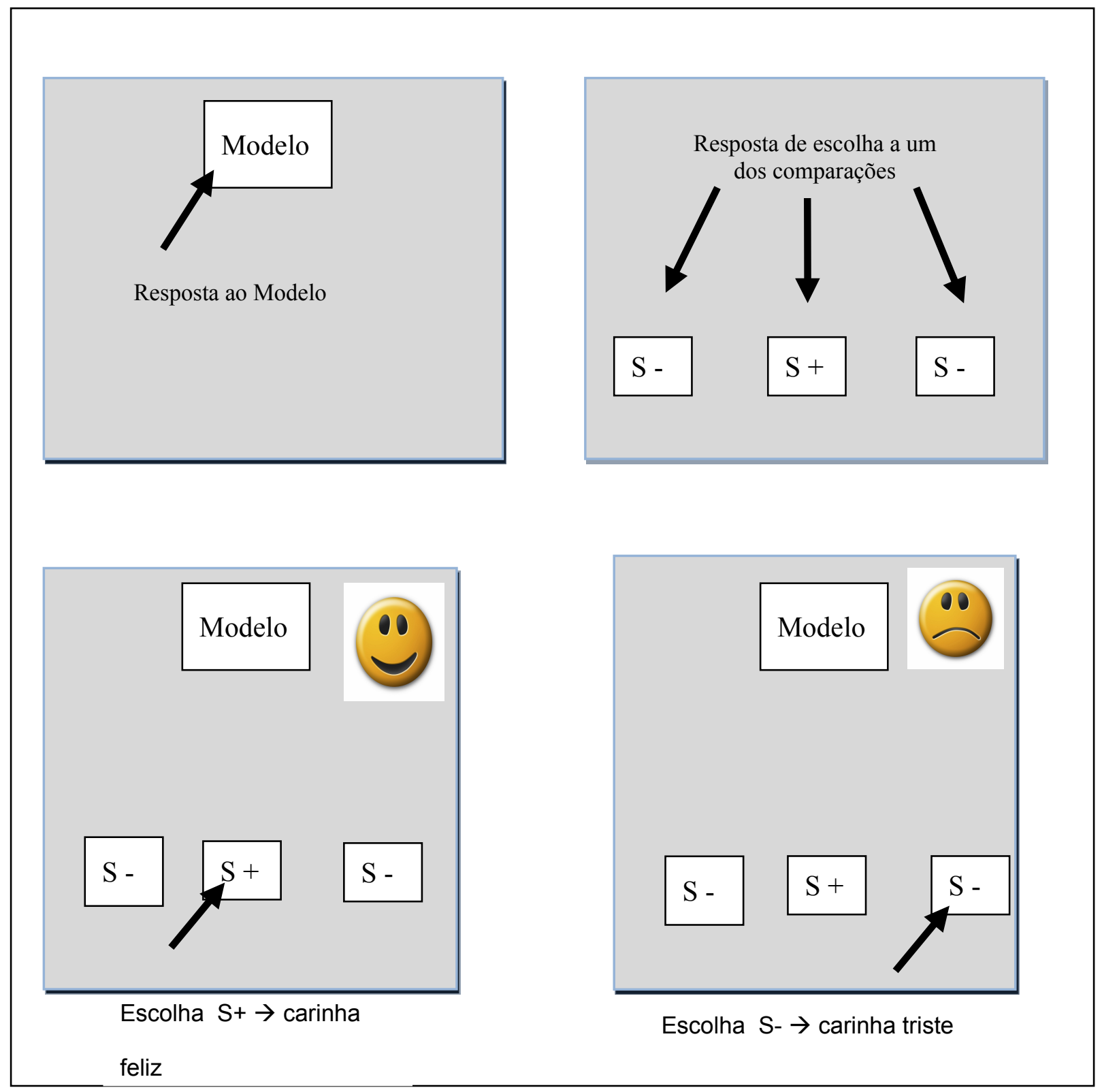

Quadro 2. llustração de tentativas de MTS utilizando o aplicativo Match!. À direita da ilustração, destaca-se - no canto superior direito - a "carinha feliz": conseqüência programada para a escolha convencionada como correta. À esquerda da ilustração, na mesma localização, destaca-se a "carinha triste": conseqüência programada para a escolha convencionada como incorreta.

\section{Tarefa experimental}

A tarefa foi composta por três fases: I) fase de pré-treino, II) fase de treino (tarefa de discriminação condicional) e III) fase de testes (equivalência; simetria e transitividade). 


\section{Fase I - Pré-treino das relações AB-BC}

Nesta fase, as tentativas tinham a função de estabelecer o desempenho de emparelhamento com o modelo. Na seqüência, o participante era submetido às fases de treino e testes, detalhadas a seguir.

O pré-treino foi utilizado para familiarizar o participante com o tipo de tarefa a ser desempenhada no computador (clicar sobre a figura central e, em seguida, clicar sobre uma das figuras periféricas); familiarizar o participante com as conseqüências indicativas de acertos e de erros e ensinar que, para cada estímulo modelo, havia um estímulo comparação correto (S+) e dois incorretos (S-).

$O$ critério de aprendizagem adotado para que o pré-treino $A B / B C$ fosse finalizado foi o de que o participante deveria apresentar, no mínimo, 11 escolhas corretas durante a sessão com blocos de 12 tentativas cada (o que corresponde a um percentual de acerto de $91 \%$ no bloco).

\section{Fase II - Treino}

A Fase II era composta de quatro etapas, sendo elas: Treino AB (etapa 1), Treino BC (etapa 2), Treino AB/BC (etapa 3), e, por último, Linha de Base AB/BC em extinção (etapa 4).

Foram utilizados três conjuntos de estímulos compostos por três estímulos cada (A1, A2 e A3 como estímulos do conjunto A; B1, B2 e B3, do conjunto B; e C1, C2 e C3, do conjunto C).

Todas as tentativas das relações $A B, B C$ e $A B / B C$ foram apresentadas em igual proporção e em ordem semi-aleatória. Cada sessão de treino das relações acima descritas era composta por 18 tentativas. O critério de aprendizagem adotado 
para que o treino de cada uma das relações fosse finalizado foi o acerto em 17 tentativas durante a respectiva fase. Depois de atingido este critério, iniciava-se a etapa seguinte da fase.

\section{Treino AB}

Primeiramente, foram treinadas as relações $A B$ (A1B1, A2B2 e A3B3). Cada tentativa se iniciava com a apresentação de um estímulo do conjunto $A(A 1, A 2$ e A3) como modelo. Respostas a esse estímulo produziam os estímulos de comparação do conjunto B (B1 B2 e B3).

\section{Treino BC}

$\mathrm{Na}$ seqüência, foram treinadas as relações $\mathrm{BC}$ (B1C1, B2C2 e B3C3). Cada tentativa se iniciava com a apresentação de um estímulo do conjunto B (B1, B2 e B3) como modelo. Respostas a esse estímulo produziam os estímulos de comparação do conjunto $C(C 1, C 2$ e C3).

\section{Treino AB/BC}

Depois de treinadas separadamente as relações $A B$ e $B C$, foi realizado ainda um treino conjunto $A B / B C$.

Linha de Base AB/BC em Extinção

Depois de concluído o ensino das discriminações condicionais $A B / B C$, as conseqüências diferenciais para respostas corretas e incorretas foram removidas, em preparação para a fase de testes. 
O participante recebeu a seguinte instrução oral: "Você está trabalhando muito bem! Agora, o computador não mostrará mais se a sua escolha está correta ou incorreta. Continue trabalhando com atenção!"

Na seqüência, o participante realizava as 12 tentativas de linha de base $A B / B C$ em extinção até atingir o critério de acerto para o encerramento da mesma: 11 escolhas corretas.

A Tabela 2 mostra as seis relações condicionais treinadas nessa fase, identificando os estímulos corretos e incorretos para cada um dos modelos.

Tabela 2. Relações condicionais treinadas na Fase II.

\begin{tabular}{|c|c|c|c|c|}
\hline \multirow[t]{2}{*}{ Relação Treinada } & \multirow[t]{2}{*}{ Modelo } & \multicolumn{3}{|c|}{ Comparações } \\
\hline & & $\begin{array}{c}\text { Correto } \\
\text { (S+) }\end{array}$ & $\begin{array}{l}\text { Incorreto } \\
\text { (S-) }\end{array}$ & $\begin{array}{c}\text { Incorreto } \\
\text { (S-) }\end{array}$ \\
\hline A1B1 & $\mathrm{A} 1$ & B1 & B2 & B3 \\
\hline A2B2 & A2 & B2 & B1 & B3 \\
\hline A3B3 & A3 & B3 & B1 & B2 \\
\hline $\mathrm{B} 1 \mathrm{C} 1$ & B1 & $\mathrm{C} 1$ & $\mathrm{C} 2$ & $\mathrm{C} 3$ \\
\hline $\mathrm{B} 2 \mathrm{C} 2$ & B2 & $\mathrm{C} 2$ & $\mathrm{C} 1$ & $\mathrm{C} 3$ \\
\hline B3C3 & B3 & C3 & C1 & $\mathrm{C} 2$ \\
\hline
\end{tabular}

Fase III - Testes

Finalmente, após a conclusão de todas as etapas da Fase II, foram testadas as seguintes relações: simetria (BA e CB), transitividade $(A C)$ e equivalência $(C A)$. $\mathrm{Na}$ fase de testes, a apresentação das conseqüências visuais e sonoras não apareceu em nenhum momento.

A Tabela 3 mostra as relações condicionais testadas. 
Tabela 3. Relações testadas na Fase III.

\begin{tabular}{|c|c|c|c|c|}
\hline \multirow[t]{2}{*}{ Teste } & \multirow{2}{*}{$\begin{array}{l}\text { Relação } \\
\text { Treinada }\end{array}$} & \multirow[t]{2}{*}{ Modelo } & \multicolumn{2}{|c|}{ Comparações } \\
\hline & & & Correto (S+) Incorreto (S-) & Incorreto (S-) \\
\hline \multirow{4}{*}{ Simetria } & $\mathrm{B} 1 \mathrm{~A} 1$ & B1 & $\mathrm{A} 2$ & A3 \\
\hline & $\mathrm{B} 2 \mathrm{~A} 2$ & B2 & $\mathrm{A} 1$ & A3 \\
\hline & B3A3 & B3 & $\mathrm{A} 1$ & $\mathrm{~A} 2$ \\
\hline & $\mathrm{A} 1 \mathrm{C} 1$ & $\mathrm{~A} 1$ & $\mathrm{C} 2$ & $\mathrm{C} 3$ \\
\hline \multirow{3}{*}{ Transitividade } & $\mathrm{A} 2 \mathrm{C} 2$ & $\mathrm{~A} 2$ & $\mathrm{C} 1$ & $\mathrm{C} 3$ \\
\hline & $\mathrm{A} 3 \mathrm{C} 3$ & A3 & $\mathrm{C} 3$ & $\mathrm{C} 2$ \\
\hline & $\mathrm{C} 1 \mathrm{~A} 1$ & $\mathrm{C} 1$ & $\mathrm{~A} 1$ & A3 \\
\hline \multirow[t]{2}{*}{ Equivalência } & $\mathrm{C} 2 \mathrm{~A} 2$ & $\mathrm{C} 2$ & $\mathrm{~A} 1$ & A3 \\
\hline & C3A3 & $\mathrm{C} 3$ & $\mathrm{~A} 1$ & $\mathrm{~A} 2$ \\
\hline \multicolumn{5}{|c|}{ Foi realizada uma sessão de teste para cada uma das relações testada } \\
\hline \multicolumn{5}{|c|}{ Houve a exposição ao teste de equivalência (CA) no início e no final da sessão de } \\
\hline \multicolumn{5}{|c|}{ teste, com a finalidade de se atestar a ocorrência da emergência atrasada. Cada } \\
\hline \multicolumn{5}{|c|}{ sessão de teste também contou com 18 tentativas. Para a constituição dos blocos } \\
\hline \multicolumn{5}{|c|}{ de tentativas, foram utilizados os mesmos critérios aplicados aos blocos de treino, } \\
\hline
\end{tabular}

Ao final dos testes, a sessão experimental era encerrada e os participantes tinham a oportunidade de escolher um dentre os itens reforçadores disponíveis. 


\section{RESULTADOS E DISCUSSÃO}

Experimento 1

Com o objetivo de, após o treino de discriminações condicionais entre estímulos abstratos, averiguar a formação de classes de estímulos equivalentes, três participantes portadores de SA foram submetidos a uma tarefa de MTS simultâneo. A Figura 1 abaixo apresenta os dados referentes aos desempenhos dos participantes P1, P2 e P3, em termos de acertos, na fase de aquisição das relações condicionais (treinos $A B ; B C$ e $A B / B C$ ). 


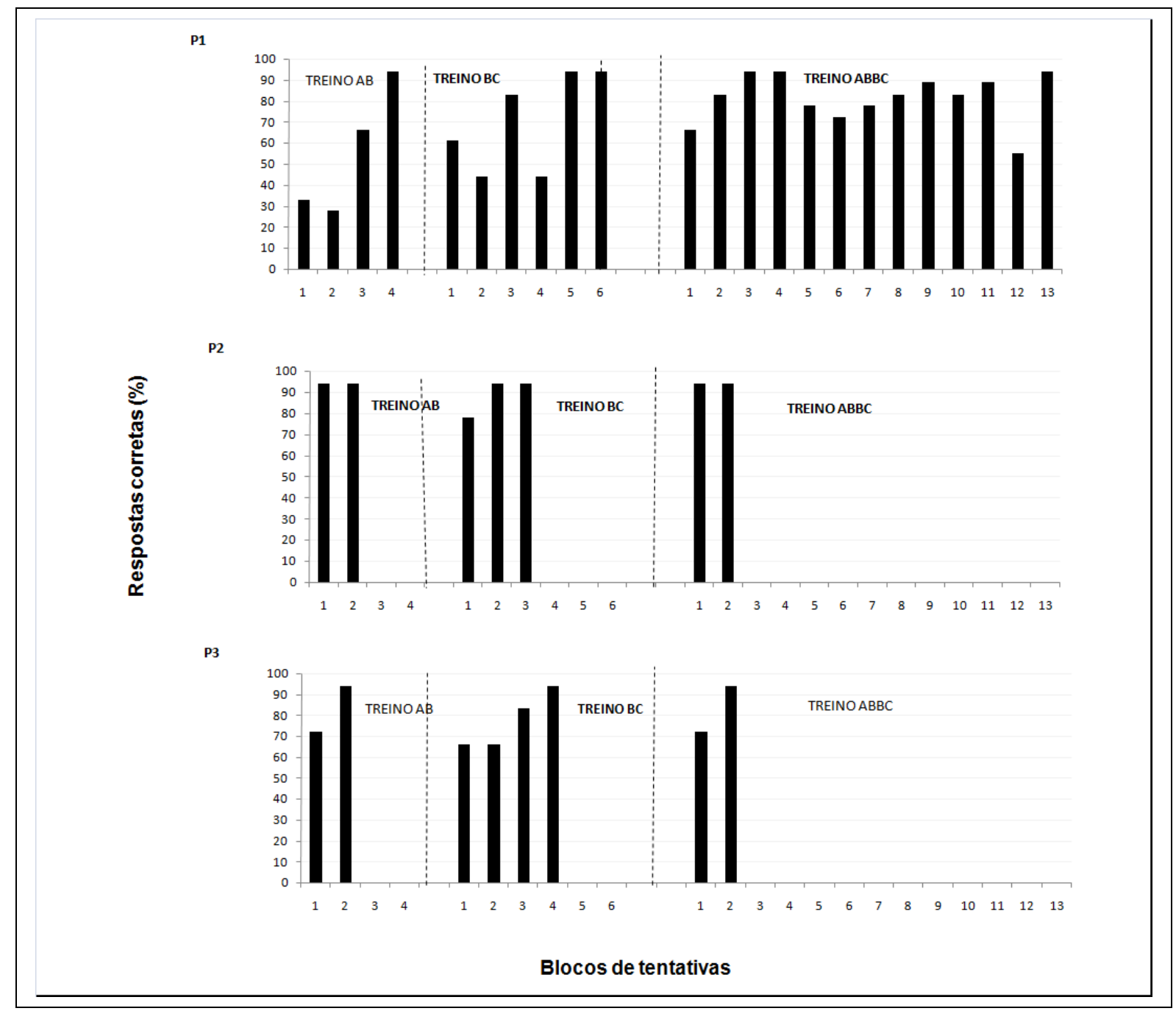

Figura 1. Desempenho dos participantes P1, P2 e P3 nos treinos do Experimento 1.

A Figura 1 ilustra o desempenho de $P 1, P 2$ e P3 no treino das relação $A B, B C$ e $A B / B C$. Cada bloco de treino continha 18 tentativas. O critério de aprendizagem adotado para que o treino de cada relação fosse finalizado foi o de que o participante deveria apresentar, no mínimo, 17 escolhas corretas durante a sessão.

No treino da relação $A B$, os participantes $P 2$ e P3 atingiram o critério de aprendizagem em 2 blocos cada um, o que representou a exposição a 36 tentativas de treino. Já o participante P3 atingiu o critério de aprendizagem em número maior de exposições: 4 blocos, ou 72 tentativas. 
No treino da relação $\mathrm{BC}$, o participante $\mathrm{P} 2$ atingiu o critério de aprendizagem em 3 blocos (54 tentativas) e P3 em 4 blocos (72 tentativas). O participante P1 atingiu o critério de aprendizagem após a exposição a 6 blocos (108 tentativas).

No treino da relação $A B / B C$, os participantes $P 2$ e $P 3$ atingiram o critério de aprendizagem em 2 blocos (36 tentativas). Novamente o participante P1 foi exposto a um número maior de blocos, 13 no total (234 tentativas), para atingir o critério de aprendizagem adotado.

Por fim, pode-se observar, durante as tentativas nas quais as relações $A B / B C$ foram apresentadas conjuntamente, que a aprendizagem de P2 e P3 a estas se apresenta de forma rápida e ascendente. $\mathrm{O}$ participante $\mathrm{P} 2$ iniciou o treino $A B / B C$ com alto percentual de acerto $(94 \%)$, porém só não atingiu o critério de aprendizagem no primeiro bloco pois suas tentativas corretas não foram consecutivas. Sendo assim, foi necessário iniciar um novo bloco de tentativas para o participante atingir o critério de aprendizagem adotado (17 tentativas corretas).

O participante $\mathrm{P} 3$ não iniciou o treino $\mathrm{AB} / \mathrm{BC}$ com um percentual de acerto tão alto quanto ao de P2 (72\% no Bloco 1), mas rapidamente atingiu o percentual de acerto de $94 \%$ no Bloco 2. Talvez P3 tenha iniciado o treino $A B / B C$ com um percentual menor que P2 devido ao fato de terem sido necessários 4 blocos até que atingisse o critério de aprendizagem no treino da relação $\mathrm{BC}$, diferentemente de $\mathrm{P} 2$, que atingiu o mesmo critério em apenas 3 blocos.

O mesmo raciocínio pode ser adotado para explicar o desempenho do participante $P 3$ no treino das relações $A B / B C$. Este participante iniciou o treino $\mathrm{AB} / \mathrm{BC}$ com um percentual de acerto de $66 \%$ e foram observadas algumas quedas no percentual de acerto ao longo do treino, o que fez com que o participante atingisse o critério de aprendizagem adotado somente no Bloco 13. Tal fato pode ser 
explicado, talvez, pelo desempenho deste participante no treino $A B$ e treino $B C . O$ desempenho nos treino (relações separadas e conjuntas) se deu de forma altamente variável (irregular) em temros de desempenho. Durante todos os treinos, este participante requereu um número maior de blocos de tentativas para atingir o critério, assim como a aprendizagem das novas relações foi mais lenta e com quedas no percentual de acerto ao longo dos treinos.

Na Figura 2 abaixo é apresentado o desempenho dos participantes nos testes para a verificação da formação de classes de estímulos equivalentes. 


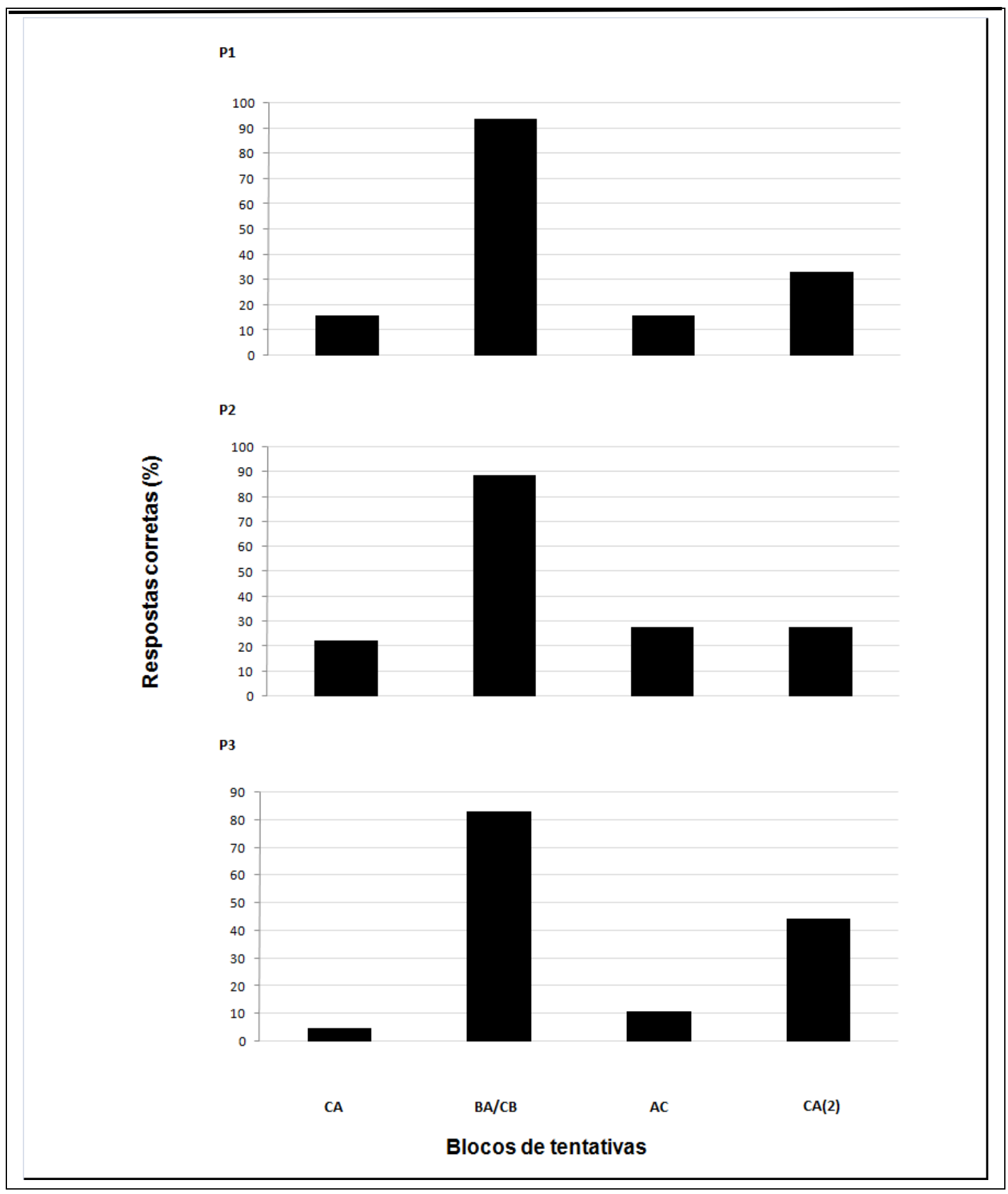

Figura 2. Desempenho dos participantes nos testes para a verificação da formação de classes de estímulos equivalentes no Experimento 1 .

De maneira geral, verifica-se falha nos testes, com a preservação do teste de simetria, no qual, observam-se resultados muito próximos entre si: P1 foi o que apresentou o maior percentual de acerto (94\%), enquanto P2 e P3 apresentaram 
percentuais de acerto de $89 \%$ e P3 83\%, respectivamente. Para todos os participantes, o percentual de acerto nos testes de equivalência e transitividade ficou abaixo dos $50 \%$ (nível do acaso).

Apesar dos prejuízos na formação de classes de estímulos equivalentes verificados nos desempenhos das participantes, destacam-se os desempenhos dos participantes nos testes de simetria (BA/CB), conforme previsto por Carrigan e Sidman (1992) e demonstrado em Johnson e Sidman (1993) e já descritos previamente. 


\section{EXPERIMENTO 2}

Considerando a importância da utilização das respostas de observação (RO's) como um recurso ao aprendizado de discriminações, em especial na linha de pesquisas sobre a formação de classes de estímulos equivalentes, o Experimento 2 propõe alterações ao procedimento de MTS descrito anteriormente.

Com o objetivo de identificar que tipos de controle (seleção ou rejeição) poderiam estar em operação na formação de classes de estímulos equivalentes, os três participantes do experimento anterior foram submetidos a uma tarefa de MTS modificada: a inclusão de respostas de observação (RO's) como um recurso para fornecer medidas dos tipos de controle vigentes (por seleção e por rejeição) ao longo das tentativas de treino e de teste na tarefa de MTS. Na tarefa, os estímulos (tanto os estímulos modelo quanto os estímulos de comparação), apresentavam-se inicialmente encobertos (janelas), tornando-se visíveis somente após a emissão de RO's. Assim, o contato do participante com os estímulos que compuseram uma tentativa de MTS, era possível por meio da emissão de respostas de observação, sendo que as respostas que produziam a conseqüência diferencial prescindiam destas RO's. 


\section{MÉTODO}

\section{Participantes}

Participaram do Experimento 2 os mesmos participantes (P1, P2 e P3) do Experimento 1.

\section{Equipamento e Estímulos}

O equipamento e os estímulos foram os mesmos descritos no Experimento 1.

\section{Procedimento e Tarefa Experimental}

O procedimento e as fases experimentais foram idênticas ao Experimento 1, com a seguinte exceção: os estímulos (modelo e comparações) foram apresentados encobertos pelo uso de janelas. Para cada estímulo encoberto havia um botão vermelho localizado imediatamente abaixo do mesmo. O contato visual dos participantes com tais estímulos era feito por meio da emissão de RO's (tocar o botão vermelho), exibindo o estímulo por 2 s.

$\mathrm{Na}$ apresentação do estímulo modelo, o participante deveria emitir a RO (o que tornava o estímulo visível) e, posteriormente, emitir uma resposta ao modelo. Essa resposta fazia com o que o estímulo modelo desaparecesse e, imediatamente, produzia a apresentação dos três estímulos de comparação (sendo um deles o S+ e os demais, dois diferentes S-), todos encobertos. Para que os estímulos pudessem ser visualizados, o participante deveria emitir a RO no botão vermelho que se referia a cada um dos três estímulos. Caso o participante não clicasse sobre o estímulo visível, após 2s, este ficaria novamente encoberto pela janela. Adicionalmente, para a resposta de escolha, o participante deveria clicar sobre um deles, estando estes 
descobertos ou não. Após emitir a $\mathrm{RO}$ e a resposta de escolha a um dos estímulos de comparação, eram apresentadas as conseqüências e a tentativa era finalizada. Seguia-se um intervalo entre tentativas (IET) de $0,5 \mathrm{~s}$ e, após este, a tentativa seguinte era iniciada.

Não havia restrição quanto ao número de aberturas da janela do modelo, apenas a exigência de uma abertura para que a tentativa seguisse adiante. No caso, apresentação dos estímulos de comparação. No entanto, cada comparação podia ser descoberto por, no máximo, três vezes, consecutivas ou não. Após três exibições de um mesmo estímulo comparação, as RO's a esse estímulo, mas não as de escolha a ele, tornavam-se sem efeito.

$\mathrm{O}$ aplicativo registrou o número total e a sequência de $\mathrm{RO}$ 's realizadas pelos participantes a cada janela, incluindo as RO`s "sem efeito".

O Quadro 3 apresenta uma ilustração de uma tentativa que compõe a tarefa de MTS empregada nesse Experimento 2. 


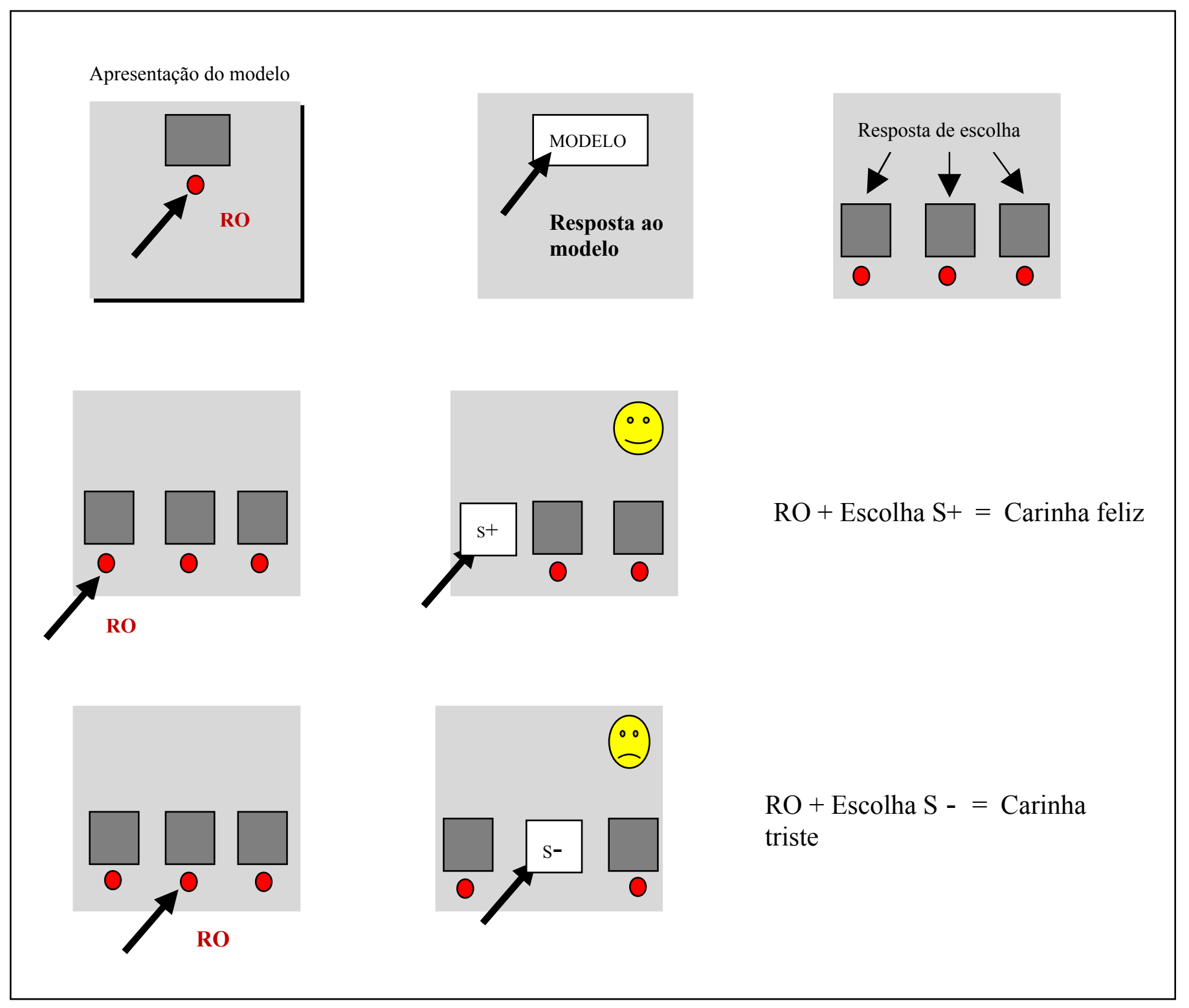

Quadro 3. llustração de tentativa de MTS com os estímulos encobertos pelas janelas utilizando o aplicativo Match! 


\section{RESULTADOS E DISCUSSÃO}

\section{Experimento 2}

O procedimento de MTS foi executado de maneira modificada, com a inclusão de respostas de observação (RO's) como um recurso para fornecer medidas dos difrentes tipos de controle de estímulos (por seleção e rejeição) ao longo das tarefas de MTS.

A Figura 3 abaixo apresenta os dados referentes ao desempenho dos participantes $\mathrm{P} 1, \mathrm{P} 2$ e P3, em percentual de acertos, na fase de aquisição das relações condicionais (treino). 


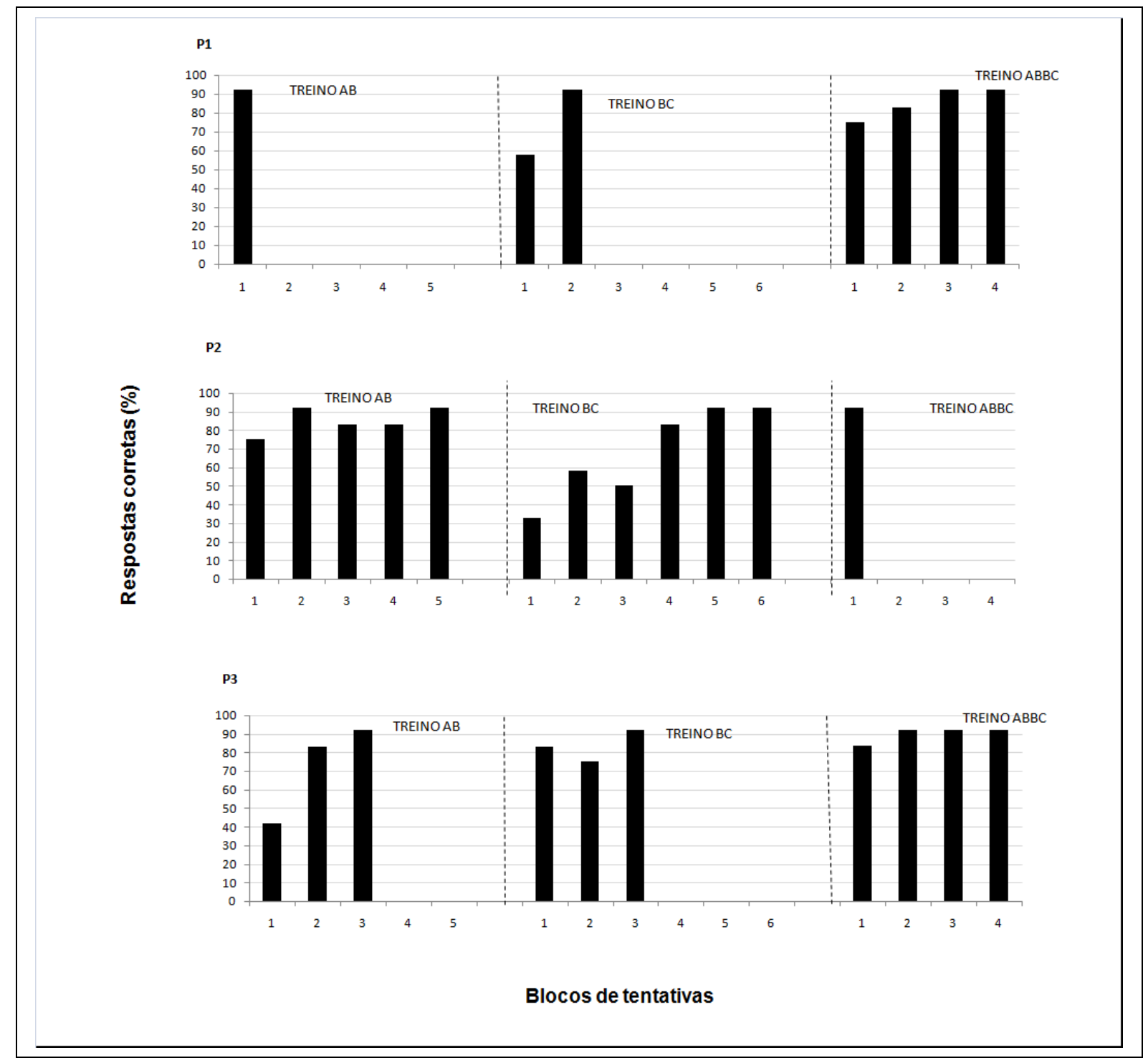

Figura 3. Desempenho dos participantes P1, P2 e P3 nos treinos do Experimento 2

Durante o treino das relaçôes $A B$ e no treino das relações $B C$, verificou-se que P1 foi o que atingiu o critério de aprendizagem mais rapidamente (1 bloco de 18 tentativas no treino $A B$ e 2 blocos ou 36 tentativas no treino $B C$ ), ao passo que $P 3$ atingiu o critério em número intermediário de exposições tanto no treino $A B$ como no treino BC: 3 blocos, ou 54 tentativas e P2 atingiu o critério com o maior número no treino das duas mesmas relações: 5 blocos, ou 90 tentativas no treino AB e 6 blocos, ou 108 tentativas no treino BC. 
No treino da relação $\mathrm{AB} / \mathrm{BC}, \mathrm{P} 1$ e $\mathrm{P} 3$ atingiram o critério de aprendizagem em 4 blocos (72 tentativas). O participante P3 atingiu o percentual de acerto de $92 \%$ nos Blocos 2, 3 e 4, porém somente no bloco 4 atingiu o critério de 17 respostas corretas consecutivas. Diferentemente de seu desempenho nos treinos $A B$ e $B C$, no treino ABBC em conjunto, P2 precisou apenas de 1 bloco (18 tentativas) para atingir o critério de aprendizagem estabelecido. Talvez o fato deste participante ter sido exposto a mais tentativas no treino $A B$ e $B C$ pode ter resultado em menor necessidade de exposição quando essas relações foram apresentadas conjuntamente.

De acordo com os resultados descritos acima, podemos observar que a aprendizagem de novas relações condicionais com a inclusão de respostas de observação (RO's) de P3 começou com um percentual de acerto de $83 \%$ no treino $A B$, e manteve-se alto durante todo o treino (92\%) e só não atingiu o critério de aprendizagem no segundo bloco pois suas tentativas corretas não foram consecutivas.

O participante $\mathrm{P} 1$ não iniciou o treino $\mathrm{AB} / \mathrm{BC}$ com um percentual de acerto tão alto $(75 \%)$, porém sua aprendizagem foi ascendente nos blocos seguintes, atingindo o critério adotado no Bloco 4.

Por fim, P2 apresentou uma aprendizagem rápida e ascendente no treino $\mathrm{AB} / \mathrm{BC}$, atingindo o critério de aprendizagem adotado em apenas um único bloco (18 tentativas). Este desempenho no treino $A B / B C$ difere de seu desempenho nos treinos $A B$ e $B C$, no qual o participante apresentou um desempenho com algumas quedas no percentual de acertos ao longo da fase com valores inferiores inclusive aos apresentados por P1 e P3. A exposição prévia e mais longa aos treinos 
separadamente de $A B$ e $B C$ parece ter sido favorável à pronta aquisição dessas relações quando apresentadas conjuntamente.

Na Figura 4 abaixo são apresentados o desempenho dos participantes nos testes para a verificação da formação de classes de estímulos equivalentes. 
P1

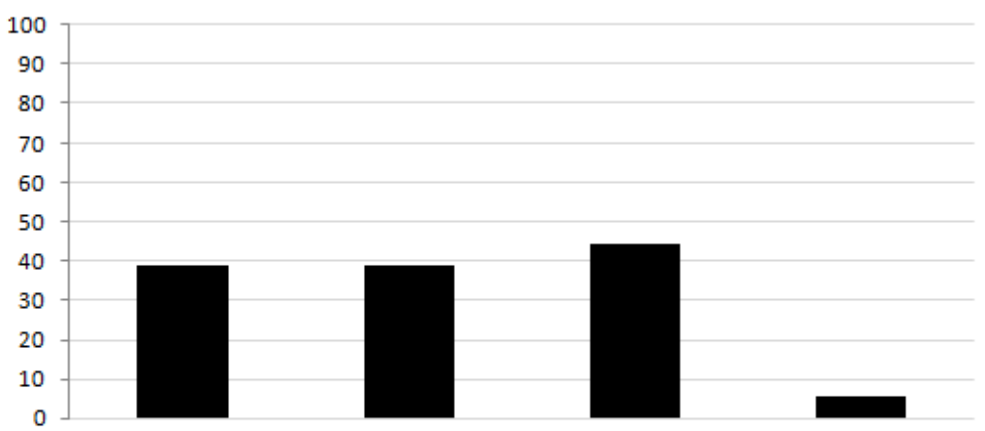

P2

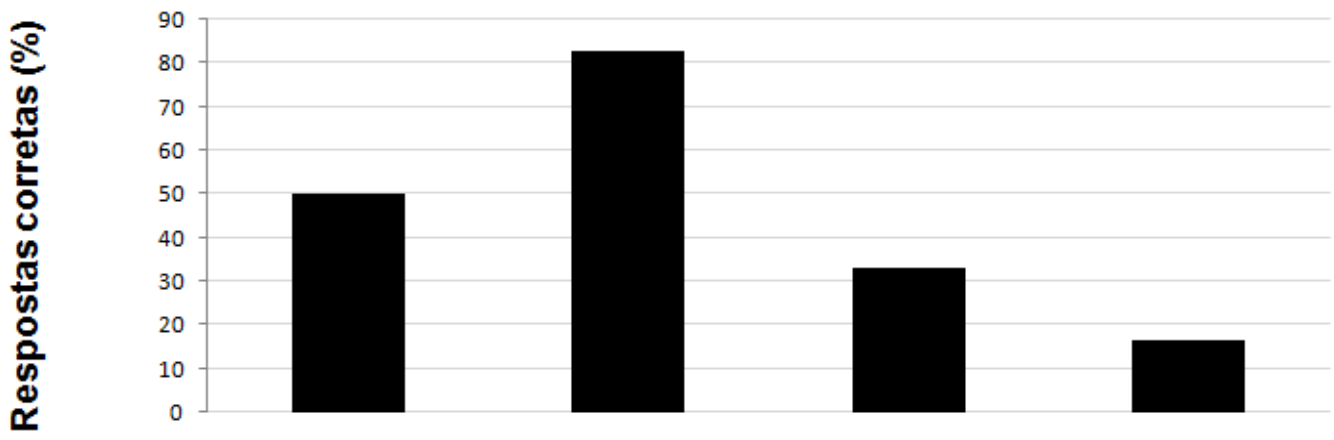

P3

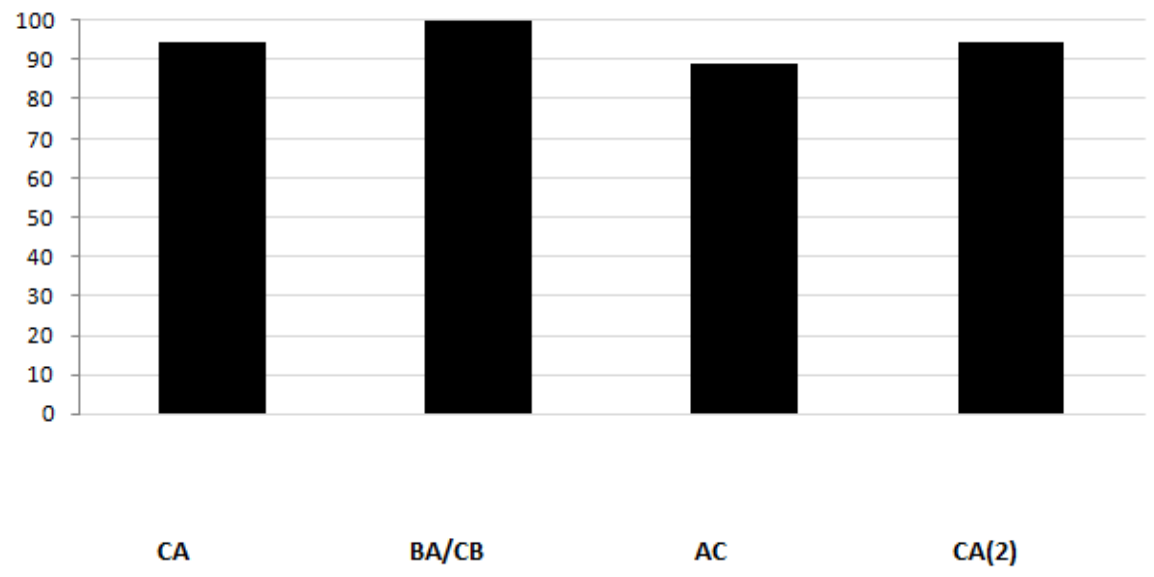

Blocos de tentativas

Figura 4. Desempenho dos participantes nos testes para a verificação da formação de classes de estímulos equivalentes no Experimento 2 . 
Nos testes, o desempenho de $\mathrm{P} 3$ foi bastante consistente no que se refere à formação de classes de estímulos equivalentes. O mínimo de acertos atingido por P3 foi o percentual de $89 \%$, resultado no teste de transitividade (AC). Já o máximo de acertos (100\%) foi atingido no teste de simetria (BA/CB). O participante também atingiu o percentual de acerto de $94 \%$ nos testes de equivalência (CA), mantendo o mesmo percentual de aprendizagem tanto na primeira quanto na segunda exposição a esse teste.

Os participantes P1 e P2 não apresentaram formação de classes de equivalência. Ambos os participantes apresentaram um desempenho abaixo dos $50 \%$ (nível acaso) nos testes, exceto pelo participante P2, que no teste de simetria atingiu um percentual de $83 \%$ de acerto. Nos testes de equivalência (CA), em ambos os participantes foram observadas algumas quedas no percentual de acertos na segunda aplicação do teste, com valores inferiores aos apresentados na primeira aplicação deste teste. Isto é, para P1 e P2, os percentuais de acertos obtidos na primeira aplicação foram de $39 \%$ e $50 \%$ respectivamente, os percentuais de acertos obtidos na segunda aplicação foram de $6 \%$ e $17 \%$ respectivamente.

A partir da análise dos dados obtidos pelos participantes no Experimento 2, pode-se concluir que a introdução de respostas de observação (RO's), como um recurso ao aprendizado de discriminações,pode, de alguma maneira, beneficiar o aprendizado em uma tarefa de MTS.

A exigência da observação ao estímulo modelo e à chance de exibir (ou não) os estímulos de comparação por meio das RO's introduzidas no presente experimento podem ter exercido algum benefício tanto na aquisição (para todos os participantes) quanto na formação das classes de estímulos equivalentes (para o participante P3). 


\section{EXPERIMENTO 3}

Tomando os resultados obtidos no Experimento 2, foi proposto o Experimento 3 no qual, além do uso de um procedimento que encobre os estímulos apresentados durante a tarefa (janelas), também houve manipulação da disponibilidade para a visualização do $S+$. Foi planejada a situação na qual em $80 \%$ das tentativas de treino das relações condicionais, o S+ estaria disponível na primeira RO emitida (em uma tentativa de produzir uma situação favorecedora do estabelecimento do controle por seleção). Também foi planejada a situação na qual em $80 \%$ das tentativas de treino das relações condicionais, o S+ estaria disponível na terceira RO emitida (em uma tentativa de produzir uma situação favorecedora do estabelecimento do controle por rejeição). A situação na qual o $S+$ foi definido a partir da primeira RO foi assumida como favorecedora do estabelecimento do controle por seleção, pois ao participante foi dada a oportunidade de selecionar o S+ sem a necessidade de emissão de novas RO's a outros estímulos (no caso, os S-). Por outro lado, a situação na qual o $\mathrm{S}+$ foi definido a partir da terceira $\mathrm{RO}$ foi assumida como favorecedora do estabelecimento do controle por rejeição, pois o participante deveria emitir pelo menos duas RO's anteriores (S-) à visualização do S+.

Para um participante, foi apresentada a seqüência na qual em $80 \%$ das tentativas de treino das relações condicionais, o $\mathrm{S}+$ estaria disponível na primeira RO emitida e, posteriormente, foi apresentada a seqüência na qual em $80 \%$ das tentativas de treino das relações condicionais, o S+ estaria disponível na da terceira RO emitida. Para o outro participante foi apresentada a seqüência inversa. Sendo assim, no Experimento 3, foram apresentadas variações metodológicas com o objetivo de favorecer o estabelecimento de um ou de outro tipo de controle, durante 
o treino das relações condicionais e verificar os efeitos destas variações no desempenho obtido nos testes.

\section{MÉTODO}

\section{Participantes}

Participaram do Experimento 3, outros dois pacientes igualmente portadores de SA, provenientes da mesma instituição dos participantes dos Experimentos 1 e 2 . Ambos participantes não tinham histórico de participação em pesquisas de psicologia e se dispuseram a participar da presente investigação, juntamente com a autorização de familiares ou responsáveis pelos mesmos. Daqui em diante, os participantes serão descritos como P4 e P5.

Abaixo, na Tabela 3, estão descritos os dados de P4 e P5 como idade cronológica, idade equivalente de acordo com repertório linguístico avaliado pelo PEABODY, classificação, segundo a avaliação por meio do PEABODY e sexo.

Tabela 3. Descrição dos participantes do Experimento 3.

\begin{tabular}{lllll}
\hline PARTICIPANTE & $\begin{array}{l}\text { IDADE } \\
\text { CRONOLOGIC } \\
\text { A NO DIA DA } \\
\text { APLICAÇÃO } \\
\text { DO TESTE } \\
\text { PEABODY }\end{array}$ & $\begin{array}{l}\text { PEABODY - } \\
\text { IDADE } \\
\text { EQUIVALENT }\end{array}$ & CLASSIFICAÇÃO & SEXO \\
& E & & & \\
& 16 ANOS E 5 & 12 ANOS E 8 & MODERADAMENT & MASC \\
MESES & MESES & $\begin{array}{l}\text { E } \\
\text { BAIXA } \\
\text { M5 }\end{array}$ & MODERADAMENT & FEM \\
& 17 ANOS E 2 & 12 ANOS E 8 & M BAIXA & \\
\hline
\end{tabular}




\section{Equipamento e Estímulos}

O equipamento e os estímulos foram idênticos aos descritos nos Experimentos 1 e 2 .

\section{Procedimento e Tarefa Experimental}

Os participantes P4 e P5 foram expostos às mesmas tarefas realizadas pelos participantes do Experimento 2, quanto ao procedimento e às fases experimentais, salvo as alterações feitas na apresentação de S+ a depender da sequência de RO's emitidas pelo participante. O propósito do Experimento 3 era o de manipular o favorecimento de um ou outro tipo de controle, seja por seleção (ou por S+) ou por rejeição (ou por S-), sobre a resposta de escolha ao estímulo com função de S+ nas tentativas de uma tarefa de MTS. Para tanto, durante as tentativas da fase de treino, a apresentação do estímulo correto $\left(\mathrm{S}^{+}\right)$dependia da primeira RO (controle por seleção) ou da terceira RO (controle por rejeição), em diferentes condições experimentais.

Apenas e unicamente durante a fase de treino, a probabilidade de exibição do estímulo correto (se após a primeira ou terceira RO) foi experimentalmente manipulada em diferentes condições, para diferentes participantes. Tanto para P4 como para P5, a apresentação de $\mathrm{S}+$ na da primeira $\left(80 \% 1^{a} \mathrm{~S}+\right)$ ou da terceira $\mathrm{RO}$ $\left(80 \% 3^{a} \mathrm{~S}+\right)$ ocorreu em $80 \%$ das tentativas da fase de treino.

Participante P4 - 80\% $3^{a} \mathrm{~S}+/ 80 \% 1^{a} \mathrm{~S}+$

O participante P4 foi submetido primeiramente à situação na qual a terceira resposta de observação produzia o estímulo correto em $80 \%$ das tentativas $\left(80 \% 3^{a}\right.$ 
S+). Após a realização das tarefas sob esta condição, P4 foi submetido à situação na qual a primeira resposta de observação produzia o estímulo correto em $80 \%$ das tentativas $\left(80 \% 1^{\text {a }} \mathrm{S}+\right)$.

Participante P5 : $80 \% 1^{a} S+/ 80 \% 3^{a} S+$

O participante P5 foi exposto à ordem inversa, sendo submetido primeiramente à situação $\left(80 \% 1^{\text {a }} \mathrm{S}+\right)$ e, posteriormente, à situação $\left(80 \% 3^{\mathrm{a}} \mathrm{S}+\right)$.

Os testes de equivalência, simetria e transitividade foram conduzidos de forma idêntica à descrita no Experimento 2, sem a definição de $S+$ a partir da seqüência de RO's. Houve a exposição ao teste de equivalência (CA) no início e no final da sessão de teste, com a finalidade de se atestar a eventual ocorrência da emergência atrasada. A emergência atrasada seria resultado do estabelecimento de novas topografias de controle no decorrer dos próprios testes (Sidman, 1994).

Devido o fato do Experimento 3 ser composto por diversas fases e variações metodológicas, a descrição dos resultados e sua discussão foi dividida em etapas (1, 2 e 3) a fim de facilitar a compreensão do leitor, conforme descrito na tabela a seguir:

\begin{tabular}{|c|c|c|}
\hline ETAPA & VARIAÇÕES METODOLÓGICAS & FASES \\
\hline 1 & & $\begin{array}{l}\text { - fase de aquisição das relações } \\
\text { condicionais (treinos) } \\
\text { - testes para a verificação da formação de } \\
\text { classes de estímulos equivalentes }\end{array}$ \\
\hline 2 & $\begin{array}{l}\text { Utilização do recurso de janelas que } \\
\text { cobriam os estímulos (tanto o modelo } \\
\text { como os comparações) }\end{array}$ & $\begin{array}{l}\text { - fase de aquisição das relações } \\
\text { condicionais (treinos) } \\
\text { - testes para a verificação da formação de } \\
\text { classes de estímulos equivalentes }\end{array}$ \\
\hline 3 & $\begin{array}{l}\text { Condição } 80 \% 3^{a} \text { S+ } \\
\text { Condição } 80 \% 1^{\text {a }} \text { S+ }\end{array}$ & $\begin{array}{l}\text { - fase de aquisição das relações } \\
\text { condicionais (treinos) } \\
\text { - testes para a verificação da formação de } \\
\text { classes de estímulos equivalentes }\end{array}$ \\
\hline
\end{tabular}

Tabela 4. Descrição das etapas do Experimento 3 


\section{RESULTADOS E DISCUSSÃO}

\section{Experimento 3}

\section{ETAPA 1}

A Figura 5 abaixo apresenta os dados referentes aos desempenhos dos participantes P4 e P5, em termos de acertos, na Etapa 1, fase de aquisição das relações condicionais (treinos $A B ; B C$ e $A B / B C$ ).

Cada bloco de treino continha 18 tentativas. O critério de aprendizagem adotado para que o treino de cada relação fosse finalizado foi o de que o participante deveria apresentar, no mínimo, 17 escolhas corretas durante a sessão.

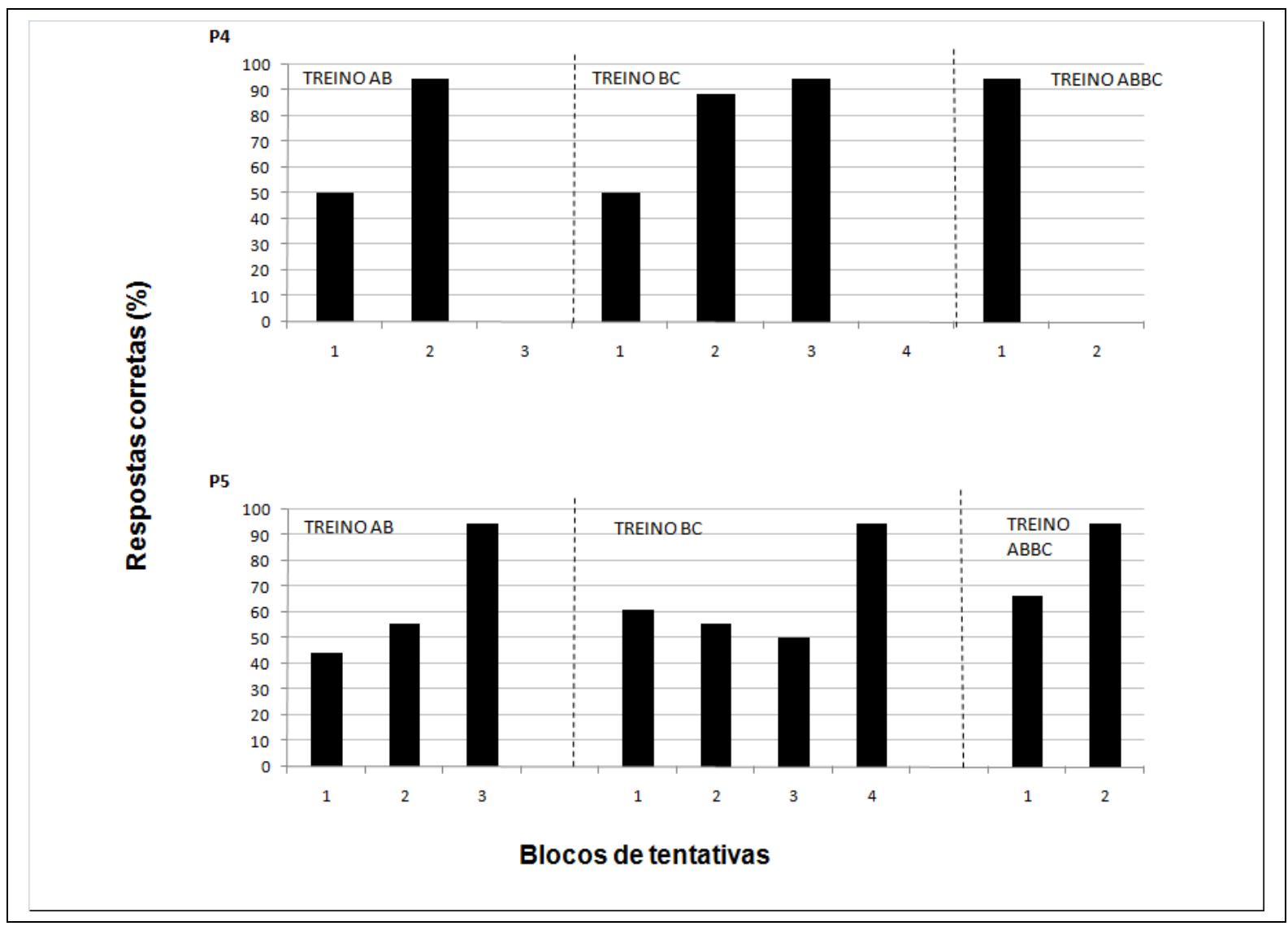

Figura 5. Desempenho dos participantes P4 e P5 nos treinos da etapa 1 do Experimento 3. 
$\mathrm{Na}$ fase de aquisição das relações condicionais, verificou-se que os participantes P4 e P5 cumpriram o critério para o encerramento do treino da relação $A B$, em, respectivamente, 2 e 3 blocos, o que representou a exposição a 36 (caso de P4) e 54 (caso de P5) tentativas de treino. O critério para encerramento do treino da relação BC foi atingido por P4 em 3 blocos (54 tentativas) e por P5 em 4 blocos(72 tentativas). Por fim, os participantes atingiram o critério para encerramento do treino das relações condicionais $A B / B C$ em 1 bloco (P4) e em 2 blocos (P5).

A partir dos resultados mencionados acima pode-se constatar que durante todos os treinos, o participante P4 requereu um número menor de blocos de tentativas para atingir o critério, assim como a aprendizagem das novas relações se apresentou de forma rápida e ascendente (o critério de encerramento do treino das relações $A B / B C$ se deu em um único bloco). Já o participante P5 apresentou uma aprendizagem mais lenta das novas relações. Em comparação a P4, o participante $\mathrm{P} 5$, durante todos os treinos, requereu um número maior de blocos de tentativas do que P4 para atingir o critério.

Na Figura 6 abaixo são apresentados o desempenho dos participantes P4 e P5 nos testes para a verificação da formação de classes de estímulos equivalentes. 


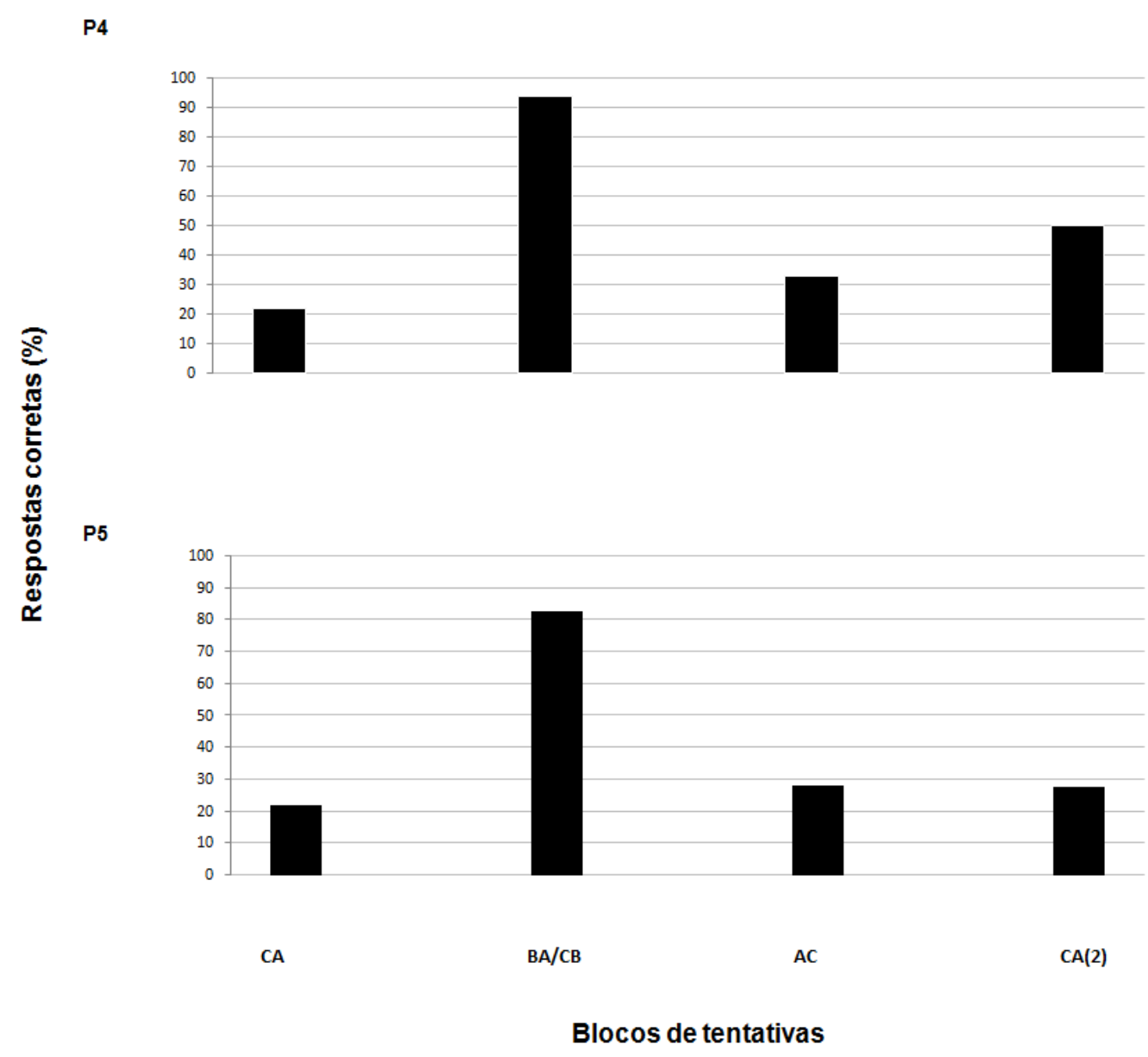

Figura 6. Desempenho dos participantes nos testes para a verificação da formação de classes de estímulos equivalentes na etapa 1 do Experimento 3 .

De um modo geral, verifica-se falha nos testes, com a preservação do teste de simetria, no qual, P4 foi o que apresentou o maior percentual de acerto $(94 \%)$, enquanto P5 apresentou percentuais de acerto de $83 \%$ (conforme descrito por Sidman \& Carrigan, 1992 e Johnson \& Sidman, 1993). Para todos os participantes, o percentual de acerto nos testes de equivalência e transitividade ficou abaixo dos $50 \%$ (nível do acaso). 


\section{ETAPA 2}

$\mathrm{Na}$ investigação da etapa 2 do Experimento 3, foi utilizado o recurso de janelas que cobriam os estímulos (tanto o modelo como os comparações). Assim, uma resposta de observação era necessária para que o participante pudesse ter o contato visual com os estímulos selecionados para a tarefa.

A Figura 7 abaixo apresenta os dados referentes aos desempenhos dos participantes P4 e P5, em termos de acertos, na fase de aquisição das relações condicionais (treinos $A B ; B C$ e $A B / B C$ ). 


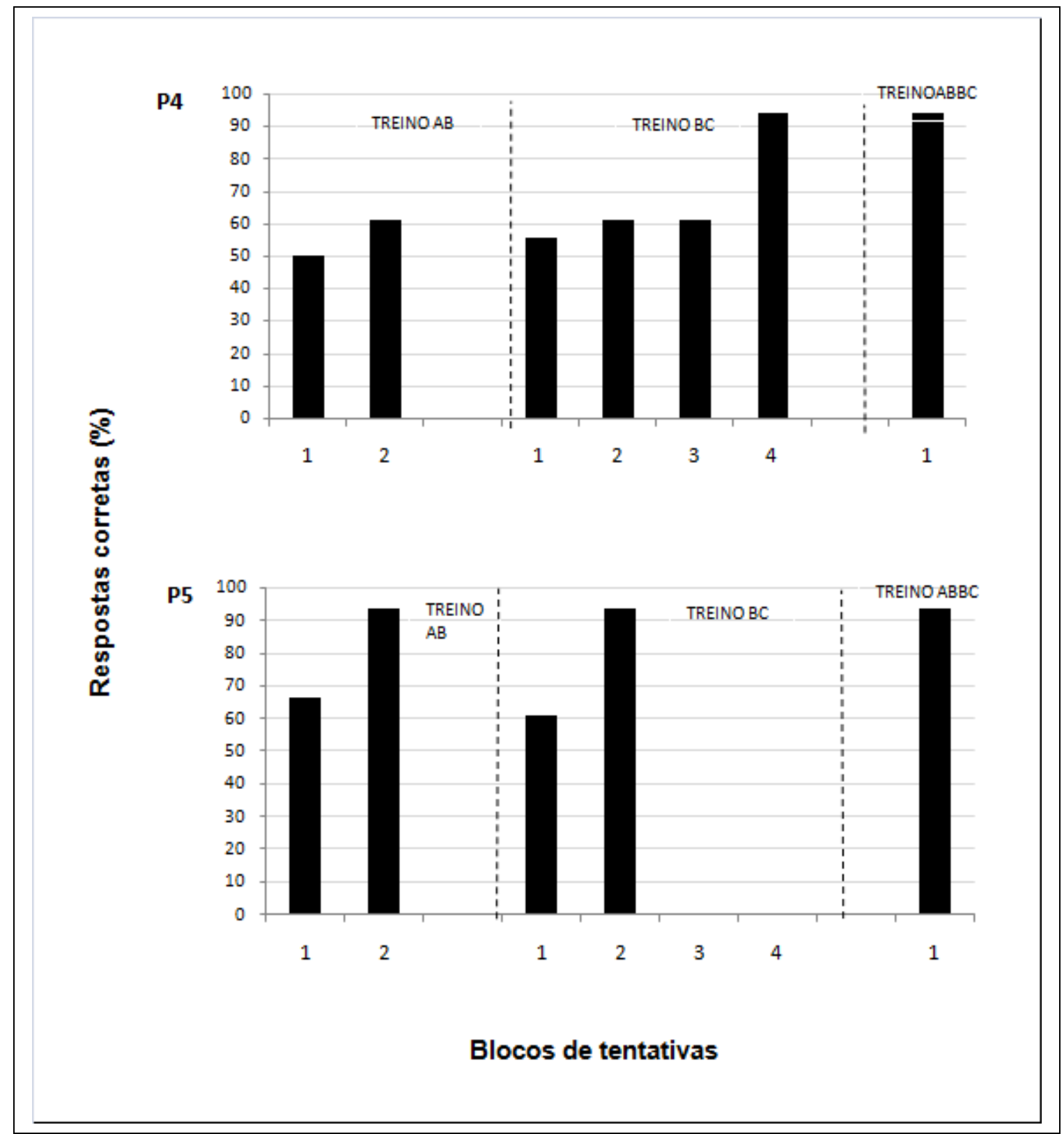

Figura 7. Desempenho dos participantes P4 e P5 nos treinos da etapa 2 no Experimento 3.

Os resultados obtidos permitem uma comparação entre a introdução de janelas e a tarefa de MTS tradicional (sem janelas), demonstrando que os desempenhos dos participantes, tanto na aquisição como na formação de classes de estímulos equivalentes, não sofreram prejuízos pela introdução de janelas à tarefa de MTS. Levando em conta o desempenho de P5, a introdução das janelas não implicou a realização de treinos com número alto de tentativas. Afinal, esse 
participante concluiu a fase de aquisição das relações condicionais (Figura 7 ) sendo exposto a um número menor de tentativas (18 tentativas para atingir o critério de encerramento no treino $\mathrm{AB} / \mathrm{BC}$ ) do que o número de tentativas ao qual foi exposto durante a mesma fase (Figura 5) na Etapa 1 (36 tentativas apra atingir o critério de encerramento no treino $A B / B C)$.

Embora sejam observadas diferenças em relação ao número de blocos de tentativas com que os participantes desta Etapa 2 atingiram o critério de encerramento do treino, o procedimento de uso de janelas sobre os estímulos foi eficaz para que ambos os participantes apresentassem uma melhora nos resultados dos testes de classes de estímulos equivalentes. Mesmo que estes não tenham formado classes de estímulos equivalentes, os participantes concluíram cada um dos testes (exceto P5 que, no teste de simetria,apresentou um percentual de acerto menor) com percentuais de acertos acima dos percentuais de acertos apresentados na Etapa 1 anteriormente descrita.

Na Figura 8 abaixo são apresentados o desempenho dos participantes P4 e P5 nos testes para a verificação da formação de classes de estímulos equivalentes na Etapa 2 . 
Figura 8. Desempenho dos participantes P4 e P5 nos testes para a verificação da formação de classes de estímulos equivalentes na Etapa 2 do Experimento 3 .

ETAPA 3

A partir dos resultados da Etapa 2, a Etapa 3 apresentou variações metodológicas com o objetivo de favorecer o estabelecimento de um ou de outro tipo de controle (seleção ou rejeição), durante o treino das relações condicionais e verificar os efeitos destas variações no desempenho obtido nos testes.

A Figura 9 apresenta o desempenho do participante P4 na Etapa 3. Este participante foi exposto primeiramente à situação na qual a terceira resposta de observação produzia o estímulo correto em $80 \%$ das tentativas $\left(80 \% 3^{a} \mathrm{~S}+\right.$ ). Posteriormente à realização das tarefas sob esta condição, P4 foi submetido à situação na qual a primeira resposta de observação produzia o estímulo correto em $80 \%$ das tentativas $\left(80 \% 1^{\text {a }} \mathrm{S}+\right)$. Os painéis à esquerda da Figura 9 apresentam os desempenhos de $\mathrm{P} 4$ no treino das relações $A B / B C$ e os desempenhos nos testes de equivalência $(C A)$, simetria $(B A / C B)$ e transitividade $(A C)$ sob a condição $80 \% 3^{a}$ S+. Os painéis à direita da Figura 9 apresentam os desempenhos desse mesmo participante no treino das relações $A B / B C$ e os desempenhos nos testes de equivalência $(C A)$, simetria $(B A / C B)$ e transitividade $(A C)$ sob a condição $\mathbf{8 0 \%} \mathbf{1}^{a}$ S+. 


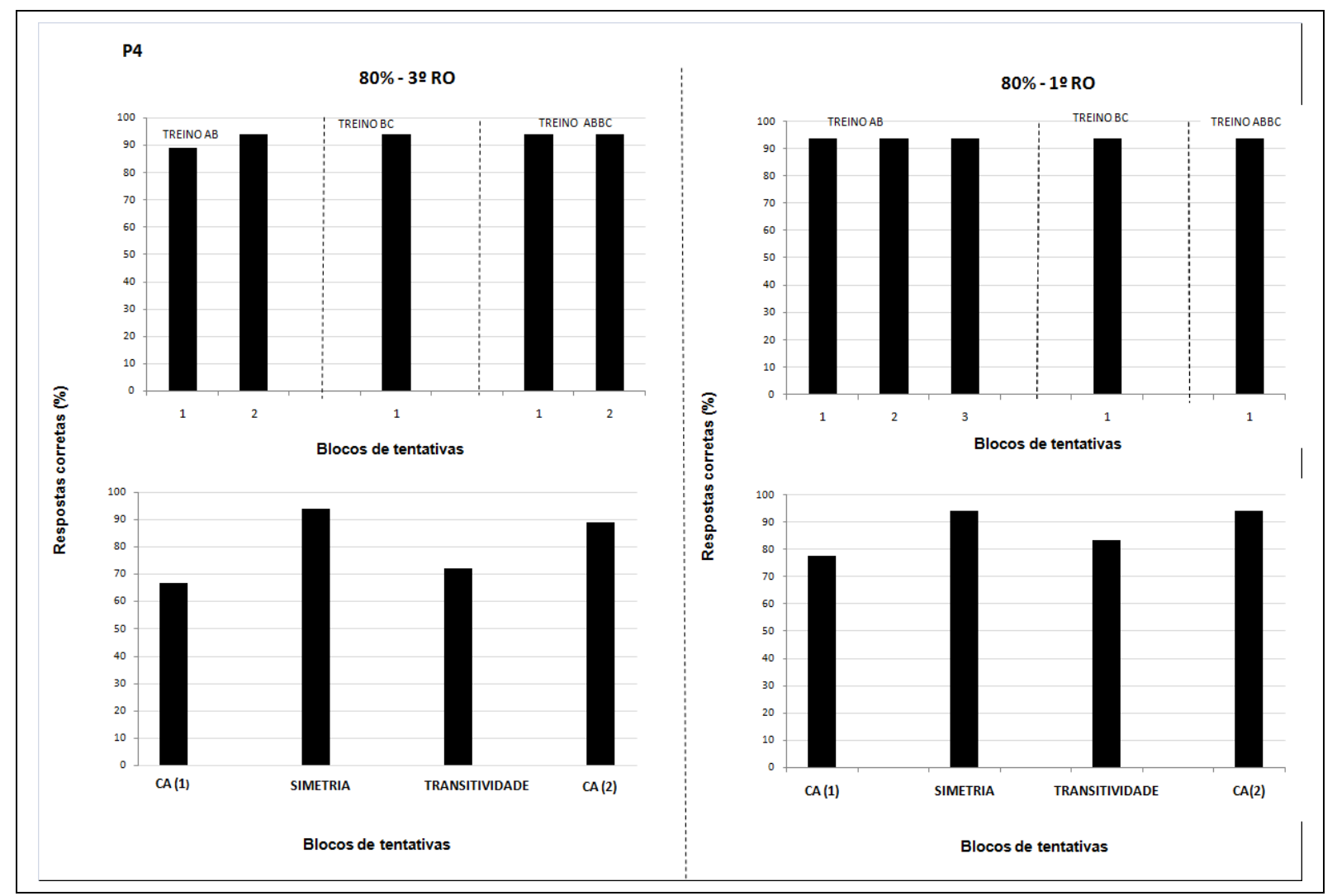

Figura 9. Desempenho nos testes do participante P4 na Etapa 3 do Experimento 3.

Conforme visto na Figura 9 acima, P4 respondeu em alta precisão durante os treinos da relação de linha de base $A B B C$, e formou classes de equivalência sob ambas as condições a que foi submetido.

A partir da análise dos resultados nos testes, identificou-se que as respostas de escolha de P4 quando este foi exposto à condição $80 \% 3^{\mathrm{a}} \mathrm{S}+$, estavam sendo controladas por uma relação de controle por rejeição ao S - (estímulo definido pelo pesquisador como escolha incorreta). Tal fato pode ser confirmado a partir da anotação das verbalizações do participante durante a execução da tarefa: "o azulzinho não combina com este (aponta o $S^{+}$), então combina com este ( toca um dos outros dois estímulos S-)” ; " se florzinha (S+) não é copinho (S-), então é este ( clica sobre estímulo S-)", entre outras verbalizações. 
Quando o participante foi submetido à situação tida como favorecedora do estabelecimento do controle por seleção (condição $80 \% 1^{\text {a }} \mathrm{S}+$ ), o seu percentual de acerto aumentou e podemos dizer que o seu responder estava sob controle discriminativo das contingências em operação. O participante P4 passou a selecionar o S+ sem emitir novas RO's a outros estímulos (no caso, os S-).

De acordo com a Análise do Comportamento, a aquisição de novos conhecimentos do ambiente, cujo resultado é uma mudança relativamente permanente no comportamento pode ser definida como aprendizagem (Matos, 1981). Baseando-se neste princípio e, após analisar os resultados da Etapa 3 no Experimento 3, podemos afirmar que P4 foi capaz de aprender as relações de equivalência propostas pelo experimentador, uma vez que atuou sob controle discriminativo nas diferentes condições a que fora submetido.

Ao analisar o desempenho de P5 na Etapa 3 do Experimento 3 (vide figura 10), mesmo com o participante apresentando um aumento no percentual de acerto quando este foi exposto a segunda situação programada ( $\left.S+80 \% 3^{a} \mathrm{RO}\right)$, podemos averiguar que o responder do participante não estava sob controle discriminativo das contingências programadas pelo experimentador. 


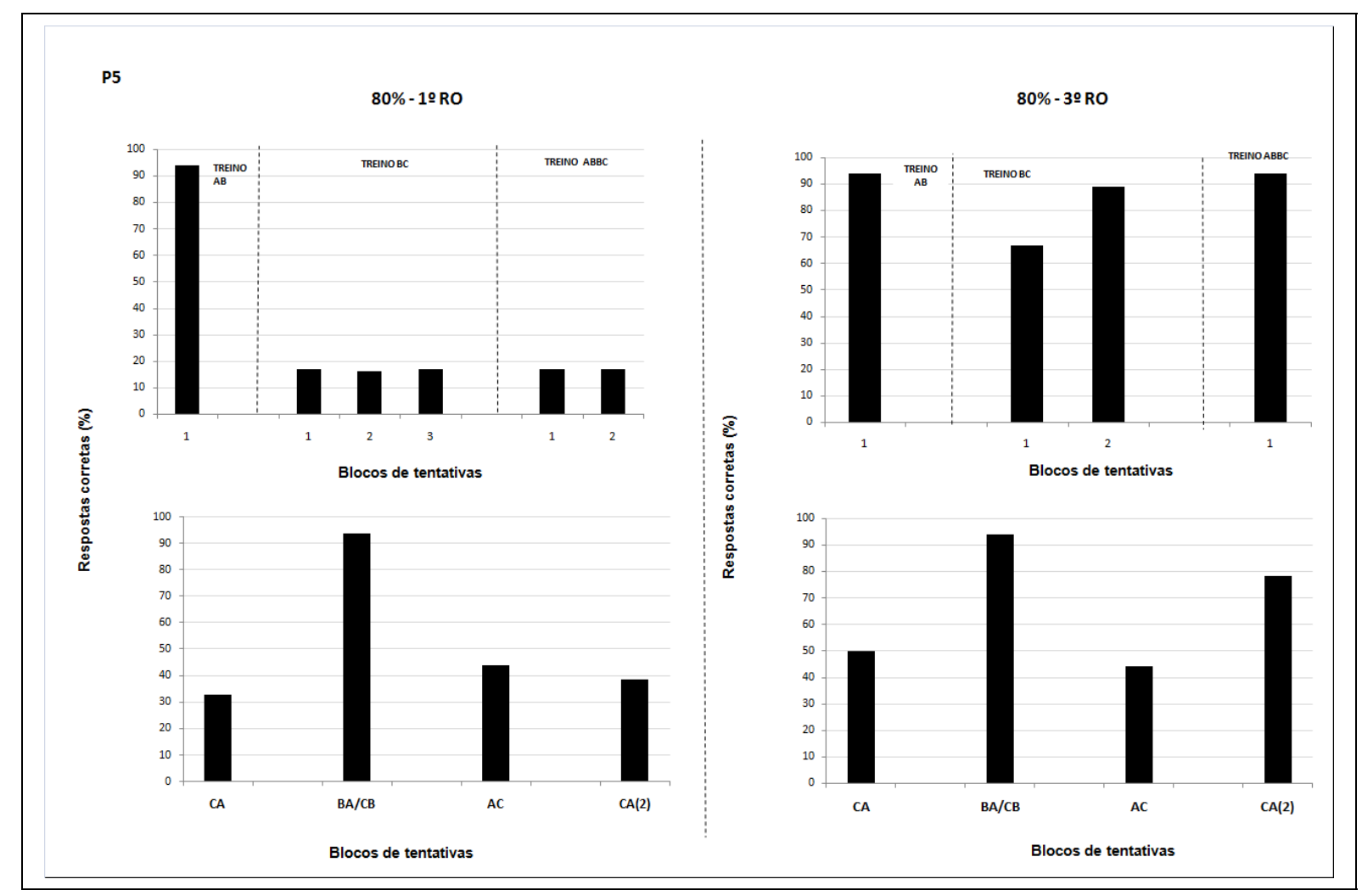

Figura 10. Desempenho nos testes do participante P5 na Etapa 3 do experimento 3.

Este desempenho pode ser atribuído aos sinais de cansaço ou saciação do participante juntamente com a dificuldade do novo repertório exigido na tarefa experimental. Isto porque, em algumas tentativas o participante emitia respostas corretas consecutivamente e depois emitia uma resposta errada, demonstrava sinais de cansaço (queixas sobre dores nas mãos; por exemplo: "estou cansado de teclar, meus dedos doem", ou ainda quando o participante estava debruçado sobre a mesa , mais próximo do lado esquerdo do monitor: "posso ficar teclando só deste lado, assim não preciso esticar muito o braço?") ou grande desinteresse pela tarefa que estava executando (por exemplo, comportamentos de não olhar para o computador, pedir para encerrar a tarefa precocemente, pedir para ir ao banheiro) nas últimas tentativas. 
Os dados descritos acima sugerem que outras condições, além das condições planejadas pelo experimentador devem ser consideradas relevantes, pois podem estabelecer controle sobre o desempenho do participante. A análise continuada não só da relação entre o desempenho do participante e as condições experimentais em vigor, mas também, da relação entre as respostas do participante P5 e o ambiente circundante ampliou a identificação de outros estímulos presentes no ambiente (diferentes dos estímulos experimentais) que possam ter exercido controle sobre o desempenho do participante P5, como por exemplo, a dificuldade de manutenção do valor reforçador dos estímulos e procedimento. Identificar e analisar tais variáveis podem ajudar na explicação do baixo controle exercido pelos estímulos reforçadores sobre as respostas de P5 e a conseqüente dificuldade para a o ensino de discriminações. 


\section{CONSIDERAÇÕES FINAIS}

O teste PEABODY foi aplicado a todos os participantes deste presente trabalho e possibilitou identificar a idade equivalente de cada participante de acordo com seu repertório lingüístico. Tal teste foi utilizado com o intuito de avaliar o repertório lingüístico de cada participante no momento da aplicação do teste.

É sabido que na área de Equivalência de Estímulos existem estudos que, ou postulam que o fenômeno da formação das classes de equivalência seria um produto da linguagem (Bentall, Beasty e Lowe, 1985) ou postulam que mesmo crianças com repertório lingüístico limitado exibem classes de equivalência (WilsonMorris \& Kirk, 1986; Sidman,1990, 2000)

Nos testes do Experimento 2, o desempenho de P3 foi bastante consistente no que se refere à formação de classes de estímulos equivalentes (atingiu o percentual de acerto de $94 \%$ nos testes de equivalência $(C A)$, apesar de seu repertório lingüístico ter sido considerado "moderadamente baixo" segundo o PEABODY. Já o participante $\mathrm{P} 1$, cujo repertório lingüístico foi considerado "normal/alto" segundo o PEABODY não apresentou formação de classes de equivalência. Tal participante ainda apresentou um desempenho abaixo dos $50 \%$ (nível acaso) nos testes. Nos testes do Experimento 3, de um modo geral, o participante P4 formou classes de equivalência, mesmo apresentando um repertório lingüístico "moderadamente baixo" de acordo com o teste PEABODY.

A tabela 5 apresentada abaixo descreve o desempenho dos participantes na formação de classes de equivalência no presente estudo e também a classificação de cada de acordo com repertório lingüístico avaliado pelo PEABODY. 
Tabela 5. Descrição dos participantes e sua classificação de acordo com repertório lingüístico avaliado pelo PEABODY

\begin{tabular}{lll}
\hline PARTICIPANTE & CLASSIFICAÇÃO & $\begin{array}{l}\text { FORMAÇÃO DE } \\
\text { CLASSES DE } \\
\text { EQUIVALÊNCIA }\end{array}$ \\
\hline P1 & NORMAL/ALTA & NÃO \\
P2 & MODERADAMENTE BAIXA & NÃO \\
P3 & MODERADAMENTE BAIXA & SIM \\
P4 & MODERADAMENTE BAIXA & SIM \\
P5 & MODERADAMENTE BAIXA & NÃO \\
\hline
\end{tabular}

A tabela acima sintetiza os dados de que dois participantes do estudo (P3 e P4), que obtiveram baixos resultados no teste PEABODY, demonstraram formação de classes de equivalência, enquanto que o participante (P1) que apresentou um alto resultado no teste PEABODY, não demonstrou formação de classes de equivalência, semelhantemente aos participantes P2 e P5 (embora o fato destes dois participantes terem apresentado baixos resultados no teste PEABODY).

Sendo assim, os resultados obtidos pelo presente estudo acrescidos das análises do teste PEABODY corroboram a posição teórica de Sidman $(1994,2000)$ de que a formação de classes de equivalência reflete um processo comportamental básico e, não pode ser reduzida nem explicada por outros processos comportamentais. As relações de equivalência têm origem nas suas próprias contingências de reforçamento e podem ocorrer em organismo que não apresentam habilidades verbais bem desenvolvidas (como os indivíduos portadores de Síndrome de Apert), contraponto o raciocínio inverso assumido por outras posições teóricas quanto à origem das relações equivalentes. 
Apesar dos prejuízos na formação de classes de estímulos equivalentes verificados nos desempenhos das participantes P1, P2 e P5, destacam-se os desempenhos dos participantes nos testes de simetria (BA/CB), conforme previsto por Carrigan e Sidman (1992) e demonstrado em Johnson e Sidman (1993). Segundo estes autores quando as respostas de escolha desses participantes estiverem sob controle por rejeição, há maior probabilidade de eles exibirem fracassos na formação de relações de equivalência, entretanto os testes de simetria seriam os únicos a serem preservados.

Os dados analisados destes participantes (principalmente de P5 conforme descrito anteriormente na seção Resultados e Discussão do Experimento 3) confirmam que o responder destes participantes foi predominantemente controlado pelo S- e evidenciam que outras relações de controle, além das relações planejadas pelo experimentador estavam vigentes. Esta identificação dos diferentes tipos de controle mantidos pelas contingências de reforçamento do presente estudo permite o desenvolvimento futuro de procedimentos que aumentem a probabilidade de ocorrência de respostas sob o controle planejado pelo experimentador e, desta maneira, diminui a probabilidade de ocorrência de respostas sob controles espúrios.

É oportuno mencionar que partir da análise do desempenho do participante P4 nos testes para a verificação da formação de classes de estímulos equivalentes na Etapa 2 e na Etapa 3 do Experimento 3, identificou-se que as respostas de escolha de P4 estavam sendo controladas por uma relação de controle por rejeição. Tal fato também pode ser confirmado a partir das verbalizações do participante durante a execução da tarefa (condição $80 \% 3^{\circ} S^{+}$) já descritas anteriormente. Nos testes da etapa 2 do Experimento 3 o particpante P4 não formou classes de equivalência e seu desempenho nos testes de simetria foi semelhante àqueles 
descritos por Carrigan e Sidman (1992) e demonstrado em Johnson e Sidman (1993). Entretanto, com as variações metodológicas propostas na etapa 3 do experimento 3, o desempenho de P4 melhorou, e o participante demonstrou formação de classes de equivalência, mesmo quando exposto a condição tida como favorecedora do estabelecimento do controle por rejeição. Entretanto, quando o participante foi submetido à situação tida como favorecedora do estabelecimento do controle por seleção (condição $80 \% 1^{a} \mathrm{~S}+$ ), o seu percentual de acerto aumentou mais e este passou a selecionar o S+ sem emitir novas RO's a outros estímulos (no caso, os S-). Por fim, o participante também demonstrou formação de classses de equivalência sob esta condição.

De um modo geral, a partir dos resultados obtidos nos Experimentos 2 e 3, o presente trabalho apresenta dados sugestivos de que as dificuldades para encontrar classes de equivalência em participantes com baixo funcionamento lingüístico podem decorrer, em grande parte, de preparação e adaptação insuficiente de procedimentos para esse tipo de sujeitos. A metodologia desenvolvida nas pesquisas é aplicável para adultos e crianças em idade pré-escolar e para deficientes mentais, mas não foi adaptada com o mesmo sucesso para populações com limitações do repertório linguístico (Barros, Galvão, Brino \& Goulart, 2005; de Rose, 2000; O’Donnel \& Saunders, 2003; Wiikinson \& Mcllvane, 2001).

Dada a importância do estudo sobre a formação de classes de estímulos equivalentes pela sua representatividade na área além de sua contribuição para a análise aplicada do comportamento, novos estudos sobre as condições consideradas necessárias e/ou suficientes para o seu estabelecimento merecem investimento. Além disso, se faz necessário que sujeitos com atraso no desenvolvimento/comportamento atípico tenham a possibilidade de adquirir ou 
refinar as habilidades cognitivas que envolvam a aprendizagem de relações entre estímulos.

O conjunto de experimentos que constituem este trabalho se insere na linha de investigação das variáveis envolvidas no processo de estabelecimento dos comportamentos ditos simbólicos em sujeitos com atraso no desenvolvimento/comportamento atípico, mais especificamente sujeitos portadores da Síndrome de Apert.

A continuidade de pesquisas se faz necessária, uma vez que procedimentos e arranjos experimentais especiais, assim como os demonstrados no Experimento 3, podem ser necessários para investigar mais detalhadamente as variáveis que controlam o estabelecimento de classes de equivalência em sujeitos com comportamento atípico. 


\section{REFERÊNCIAS}

Alonso, N. \& Cintra Jr, W. (2002). Cranioestenoses e craniofacioestenoses. In: Mélega, J.M. Cirurgia Plástica Fundamentos e arte - Cirurgia Reparadora de Pescoço e Crânio. Rio de Janeiro: Editora Médica e Científica.

Araújo Jr, E., Guimarães Filho, H.A., Pires, C.R., Zanforlim Filho, S.M., Nardozza, L.M.M. \& Moron, A.F. (2006). Diagnóstico pré e pós-natal de craniossinostose: ensaio iconográfico. Revista Imagem, 28(1),19-23. São Paulo.

Barros, R. S. (1996). Análise do comportamento: Da contingência de reforço à equivalência de estímulos. Caderno de Textos de Psicologia,1(1), 7-14.

Barros, R. S., Galvão, O. F., Brino, A. L. F., Goulart, P. R. K. \& Mcllvane, W. J. (2005). Variáveis de procedimento na pesquisa sobre classes de equivalência: contribuições para o estudo do comportamento simbólico. Revista Brasileira de Análise do Comportamento, 1, 1, 15-27.

Bentall, R.P., Lowe, C.F. Y beasty, A. (1985). The role of verbal behavior in humanlearning: Development diferences. Journal of Experimental Analysis of Behavior, 43, 165-181.

Campis, L.B. (1991). Children with Apert syndrome: developmental and psychologic considerations. Clin Plast Surg, v 18(2). 409-16.

Carr, D., Wilkinson, K. M., Blackman, D., \& Mcllvane, W. J. (2000). Equivalence classes in individuals with minimal verbal repertoires. Journal of the Experimental Analysis of Behavior, 74(1), 101-114.

Catania, A.C. (1999). Aprendizagem: Comportamento, Liguagem e Cognição. Artmed: Porto Alegre.

Carrigan, P. F., Jr. e Sidman, M. (1992). Conditional discrimination and equivalence relations: A theorical analysis of control by negative stimuli. Journal of the Experimental Analysis of Behavior, 58, 183-204. 
Cohen, MM., Jr .(2000). Syndromes with craniosynostosis. In: Cohen MM Jr, MacLean R.E. Craniosynostosis: Diagnosis, Evaluation, and Management, Second Edition, Oxford University Press, New York, pp. 309-441.

Collares, M.V.M., Dogliotti, P. \& Rangel, L.C.A. (2002). Disostoses Craniofaciais. In: Mélega, J.M. Cirurgia Plástica Fundamentos e arte - Cirurgia Reparadora de Pescoço e Crânio. Rio de Janeiro: Editora Médica e Científica.

Cumming, W. W., \& Berryman, R. (1965). The complex discriminated operant: studies of matching-to-sample and related problems. In D. J. Mostofsky (Org.) Stimulus generalization, pp. 284-330. Standford, CA: Standford University Press.

Da Costa, A.C., Walters, I., Savarirayan, R., Anderson, V.A., Wrennall, J.A. \& Meara, J.G. (2006). Intellectual outcomes in children and adolescents with syndromic and nonsyndromic craniosynostosis. Plastic and Reconstructive Surgery. 118 (1), 175 -181. Michigan.

Devany, J.M.; Hayes, S.C. e Nelson, R.O. (1986) Equivalence class formation in language-able and languagedisabled children. Journal of the Experimental Analysis of Behavior, 46, 243-257.

de Rose, J. C. (1993). Classes de estímulos: implicações para uma análise comportamental da cognição. Psicologia: teoria e pesquisa. 9, 283-303.

de Rose, J. C., Mcllvane, W. J., Dube, W. V., Galpin, V. C. \& Stoddard, L. T. (1988). Emergent simple discriminations established by indirect relations to differential consequences. Journal of the Experimental Analysis of Behavior, 50, 1-20.

Diament, A.; Cypel, S. (1996). Neurologia Infantil. 3. ed. São Paulo: Atheneu. 
Dube, W. V., Mcllvane, W. J., Callahan, T. D. \& Stoddard, L., T. (1993). The search for stimulus equivalence in nonverbal organisms. The psychological record,43, 761-778.

Dube, W. V. \& Mcllvane, W. J. (1995). Stimulus-reinforcer relations and emergent matching-to-sample. The Psychological Record, 45, 591-612.

Dugdale, N.A. e Lowe, C.F. (1990) Naming and stimulus equivalence. Em, D.E. Blackman and H. Lejueune (Orgs.). Behavior Analysis in Theory and Practice: Contributions and Controversies. Brighton, UK.: Lawrence Erlbaum Associates. 115-138.

Dunn, L. M., \& Dunn, L. M. (1981). Peabody picture vocabulary test - Revised. Circle Pines, MN: American Guidance Service.

Gorlin, R. J.; Toriello, H. V.; Cohen, M. M. JR. (1995). Genetic hearing loss associated with musculoskeletal disorders: Hereditary hearing loss and its syndromes. New York: Oxford University Press.

Green, G., \& Saunders, R. R. (1998). Stimulus equivalence. In K. A. Lattal, \& M. Perone (Eds.), Handbook of research methods in human operant behavior (pp. 229-262). New York: Plenum.

Goulart, P.R.K., Mendonça, M.B., Barros, R.S., Galvão, O.F., \& Mcllvane, W.J. (2005). A note on Select and Reject Controlling Relations in the Simple Discrimination of Capuchin Monkeys (Cebus apella). Behavioural Processes 69, 295-302.

Hayes, S.C. (1991) A relational control theory of stimulus equivalence. Em, S.C. Hayes and P. N. Chase (Orgs.), Dialogues on Verbal Behavior. Reno, NV: Contex Press. 
Horne, P.J., \& Lowe, C.F. (1996). On the origins of naming and other symbolic behavior. Journal of the Experimental Analysis of Behavior, 65, 185-241.

Hübner, M. M. (1997). O paradigma de equivalência e suas implicações para a compreensão e emergência de repertórios complexos. Em R. A. Banaco (Org.), Sobre comportamento e cognição: Aspectos teóricos, metodológicos e de formação em análise do comportamento e terapia cognitivista (pp. 423-430). São Paulo: ARBytes.

Johnson, C. e Sidman, M. (1993). Conditional discrimination and equivalence relations: Control by negative stimulus. Journal of the Experimental Analysis of Behavior, 59, 333-347.

Kay, J.B., Tubbergen, M.V., Warshawsky, S \& Buchman, S.R. (2005). Social response in children with severe cognitive impairments: Factors in craniofacial surgery decision-making. Plastic and Reconstructive Surgery. 116 (2), 408-416. Michigan.

Kobinger, M.E.B.A., Bricks, L.F. \& Ferrer, A.P.S. (1998). Assimetria craniofacial como forma de apresentação da cranioestenose: relato de caso. Revista de Pediatria da USP, 21 (4), 254-260.

Lajeunie E., Le Merrer. M., Bonaïti-Pellie. C., Marchac. D. e Renie.r D. (1995). Genetic study of nonsyndromic coronal craniosynostosis. American Journal of Medical Genetics. 55(4), 500-504. Paris.

LeBlanc, L., Miguel, C. F., Cumming, A., Goldsmith, T., \& Carr, J. E. (2003). The effects of three stimulus-equivalence testing conditions on emergent $U$. S. geography relations of children diagnosed with autism. Behavioral Interventions, 18, 279-289. 
Lowe, C.F. (1983) Radical behaviorism and human psychology. Em, G.C.L. Davey (Org.). Animal Models of Human Behavior. Wiley: New York.

Maguire, R. W., Stromer, R., Mackay, H. A., \& Demis, C. A. (1994). Matching to complex samples and stimulus class formation in adults with autism and young children. Journal of Autism and Developmental Disorders, 24, 753-772.

Matos, M. M. (1981). O controle de estímulos sobre o comportamento. Psicologia, $7(2)$, pp. $1-15$

Matos, M. A. (1999). Controle de estímulo condicional, formação de classes conceituais e cognição. Revista Brasileira de Terapia Comportamental e Cognitiva, 1, 158-178.

Matos, M. A. \& Hübner-D'Oliveira, M. M. (1992) Equivalence relations and reading. In S. C. Hayes \& L. J. Hayes (Eds.), Understanding verbal relations (pp. 83-94). Reno: Context Press.

Mcllvane, W. J., Serna, R. W., Dube, W. V., \& Stromer, R. (2000). Stimulus control topography coherence and stimulus equivalence: Reconciling test outcomes with theory. In J. Leslie \& D. E. Blackman (Eds.), Issues in experimental and applied analyses of human behavior (pp. 85-110). Reno: Context Press.

Mcllvane, W. J. \& Dube, W. V. (2003). Stimulus control topography coherence theory: Foundations and extensions. The Behavior Analyst, 26, 195-213.

Medeiros, J. G \& Silva, R. M. F. Efeitos de testes sobre a generalização em crianças em processo de alfabetização. Psicologia reflexão e crítica, 2002, (3), 587-602.

Moreira, M. B.; Todorov, J. C.; Nalini, L. E. G.. Algumas considerações sobre o responder relacional. Revista Brasileira de Terapia Comportamental e Cognitiva., São Paulo, v. 8, n. 2, dez. 2006 
O'Donnell, J., \& Saunders, K. J. (2003). Equivalence relations in individuals with language limitations and mental retardation mental retardation, below average level of intellectual functioning, usually defined by an IQ of below 70 to 75 , combined with limitations in the skills necessary for daily living. . Journal of the Experimental Analysis of Behavior, 80, 131-157.

Okkerse, J.M.F., Beemer, F.A., Mellenbergh, G.J., Wolters, W.H.G. \& Heineman - de Boer, J.A. (2005). Risk factors for visual-motor integration and intelligence in children with craniofacial anomalies. 16 (4), 517 -524. Tampa.

Opperman, L.A. (2000).Cranial sutures as intramembranous bonegrowth sites. Developmental Dynamics. V 219 (4), 472 -475.

Panchal, J., Uttchin, V. (2003). Management of craniosynostosis. Plastic Reconstructive Surgery. V 111 (6). 2032 -2048.

Patton, M. A.; Goodship, J.; Hayward, R.; Lansdown, R., (1988). Intellectual development in Apert's syndrome: a long term follow up of 29 patients. J. Med. Genet, V 25.164-167.

Ray, B. A. (1969). Selective attention: The effects of combining stimuli which control incompatible behavior. Journal of Experimental Analysis of Behavior, 12, 539550.

Renier, D., Arnaud, E., Cinalli, G., Sebag, G., Zerah, M., and Marchac, D. (1996). Prognosis for mental function in Apert's syndrome. J. Neurosurg. 85: 66 -72 .

Sarimski, K. (1997). Cognitive functioning of young children with Apert's syndrome, Genet Couns. V 8(4).317-22 .

Shuper, A., Merlob. P., Grunebaum, M. \& Reisner S.H. (1985). The incidence of isolated craniosynostosis in the newborn infant. American Journal of Disabilities Child. $139,85-86$. 
Sidman, M. (1971). Reading and auditory-visual equivalencies. Journal of Speech and Hearing Research, 14, 5-13.

Sidman, M. (1986). Functional analysis of emergent verbal classes. Em T. Thompson \& M. D. Zeiler (Orgs.), Analysis and Integration of Behavioral Units (pp. 213-245). Hillsdale, N. J.: Erlbaum.

Sidman, M. (1990). Equivalence relations: Where do they come from? Em D. E. Blackman \& H. Lejeune (Orgs.), Behaviour analysis in theory and practice: Contributions and controversies. Brighton, U.K.: Erlbaum.

Sidman, M. (1994). Equivalence relations and behavior: A research story. Boston: Authors Cooperative.

Sidman, M. \& Cresson, O. (1973). Reading and crossmodal transfer of stimulus equivalencies in severe mental retardation. American Journal of Mental Deficiency, 77, 515-523

Sidman, M. \& Tailby, W. (1982). Conditional discrimination vs. matching to sample: An expansion of the testing paradigm. Journal of the Experimental Analysis of Behavior, 37(1) 15-22.

Sidman, M.; Rauzin, R.; Lazar, R.; Cunningham, S.; Tailby, W. e Carrigan, P. (1982). A search for symmetry in the conditional discrimination of rhesus monkeys, baboons, and children. Journal of the Experimental Analysis of Behavior, 37, 2344.

Sidman, M. (2000). Equivalence relations and the reinforcement contingency. Journal of the experimental analysis of behavior, 74, 127-146.

Skinner, B.F. (1945) The operacional analysis of psychological terms.Psychological Review, 52, 270-277. 
Skinner, B.F. (1953). Ciência e Comportamento Humano. Tradução: Todorov, J.C e Azzi, R. (2003). São Paulo: Martins Fontes.

Skinner, B. F. (1974/2003). Sobre o behaviorismo (8ª Edição). São Paulo: Editora Cultrix

Speltz, M.L., Kapp-Simon, K.A., Cunningham, M., Marsh, J. \& Dawson, G. (2004). Single-suture craniosynostosis: A review of neurobehavioral research and theory. Journal of Pediatric Psychology, 29(8), 651-668. Seatle.

Todorov, J. C. (1985). O conceito de contingência tríplice na análise do comportamento. Psicologia: Teoria e Pesquisa, 1, 75-88.

Tomanari, G. Y. (2005). O papel da nomeação na formação de classes de estímulos equivalentes. In: H. Guilhardi \& N. C. de Aguirre (Orgs.). Sobre Comportamento e Cognição. 1a. Ed. Vol. 15, pp. 192-198. Santo André (SP): ESEtec.

Tomanari, G. Y. , Sidman, M., Rubio, A. R. \& Dube, W. V. (2006). Equivalence classes with requirements for short response latencies. Journal of Experimental Analysis of Behavior, 85, 349-369.

Velasco, S. M.; Tomanari, G. Y. Efeitos do treino de discriminações condicionais sobre a aquisição de relações simétricas e transitivas. Acta Comportamentalia, v. 17, p. 97-116, 2009.

Vogel, F.; Motulsky, A. (2000). Genética Humana. Problemas e abordagem. Trad. Paulo Armando Motta. Rio de Janeiro: Guanabara Koogan.

Vigotsky, L.S. (1986). Thought and language (Alex Kozulin, Trans.). Cambridge: The MIT Press. (Russian Original Published 1934). 
Whaley, D. L. \& Malott, R. W. (1981). Princípios elementares do comportamento ( M. M Matos, M.L. Ferrara \& C. F. Santoro, Trads.). São Paulo: EPU ( Trabalho originalmente publicado em 1971).

Wilkie, A. (1997). Craniosynostosis: genes and mechanisms. Human Molecular Genetics. V10(6). $1647-1956$.

Wilkinson, K. M. \& Mcllvane, W. J. (2001). Methods for studying symbolic behavior and category formation: Contributions of stimulus equivalence research. Developmental Review, 1-20.

Yacubian, A., Palhares, A. Giglio, A. Gabarra, R.C., Zanini, S., Portela, L., Silva, M.V., Perosa, G.B., Abramides, D. \& Plese, J.P.P. (2005). Apert syndrome: factors involved in the cognitive development. Arquivos de Neuro-Psiquiatria, Brasil, v. 63, p. 963-968.

Zeisel, S.A.; Roberts, J. E. (2003). Otitis Media in Young children With Disabilities. Infants \& Young Children, 16: 106-119. 


\section{ANEXOS \\ Termo de Consentimento Livre e Esclarecido}

Título do estudo:

Pesquisador(a) responsável:

Instituição / Departamento:

Endereço do(a) pesquisador(a) responsável:

Telefone do(a) pesquisador(a) responsável para contato:

Local da coleta de dados:

Prezado(a) Senhor(a):

1

2 - Você está sendo convidado (a) a participar desta pesquisa de forma totalmente voluntária.

3 - Antes de concordar em participar desta pesquisa, é muito importante que você compreenda as informações e instruções contidas neste documento.

4 - Os pesquisadores deverão responder a todas as suas dúvidas antes que você se decidir a participar.

5 - Você tem o direito de desistir de participar da pesquisa a qualquer momento, sem nenhuma penalidade e sem perder os benefícios aos quais tenha direito. .

Procedimentos. Sua participação nesta pesquisa consistirá apenas em executar algumas tarefas juntamente com o experimentador.

Benefícios. Esta pesquisa trará maior conhecimento sobre o tema abordado, com benefício direto para pessoas portadoras da Síndrome de Apert. 
Riscos. A participação nesta pesquisa não representará qualquer risco de ordem física ou psicológica para você.

Sigilo. As informações fornecidas por você terão sua privacidade garantida pelos pesquisadores responsáveis. Os sujeitos da pesquisa não serão identificados em nenhum momento, mesmo quando os resultados desta pesquisa forem divulgados em qualquer forma.

Ciência e de acordo do participante (sujeito da pesquisa)

Ciente e de acordo com o que foi, anteriormente exposto, eu estou de acordo em participar desta pesquisa, assinando este consentimento em duas vias, ficando com a posse de uma delas.

Campinas, de de 20 .

Assinatura do sujeito de pesquisa

Representante legal (para casos de pacientes menores de 18 anos, analfabetos, semi-analfabetos ou portadores de deficiência auditiva ou visual).

Ciência do (a) pesquisador (a) responsável pelo projeto:

Declaro que obtive de forma apropriada e voluntária o Consentimento Livre e Esclarecido deste sujeito de pesquisa ou representante legal para a participação neste estudo.

Campinas, de 200

Assinatura do responsável pelo projeto 